IZA DP No. 7567

Do Institutions Affect Social Preferences?

Evidence from Divided Korea

Byung-Yeon Kim Syngjoo Choi Jungmin Lee

August 2013
Sokbae Lee

Kyunghui Choi 


\title{
Do Institutions Affect Social Preferences? Evidence from Divided Korea
}

\author{
Byung-Yeon Kim \\ Seoul National University
}

Syngjoo Choi

University College London

\author{
Sokbae Lee \\ Seoul National University \\ Kyunghui Choi \\ University of Tokyo
}

\section{Jungmin Lee \\ Sogang University \\ and IZA}

University of Tokyo

\section{Discussion Paper No. 7567 \\ August 2013}

\author{
IZA
}
P.O. Box 7240
53072 Bonn
Germany

\author{
Phone: +49-228-3894-0 \\ Fax: +49-228-3894-180 \\ E-mail: iza@iza.org
}

\begin{abstract}
Any opinions expressed here are those of the author(s) and not those of IZA. Research published in this series may include views on policy, but the institute itself takes no institutional policy positions. The IZA research network is committed to the IZA Guiding Principles of Research Integrity.

The Institute for the Study of Labor (IZA) in Bonn is a local and virtual international research center and a place of communication between science, politics and business. IZA is an independent nonprofit organization supported by Deutsche Post Foundation. The center is associated with the University of Bonn and offers a stimulating research environment through its international network, workshops and conferences, data service, project support, research visits and doctoral program. IZA engages in (i) original and internationally competitive research in all fields of labor economics, (ii) development of policy concepts, and (iii) dissemination of research results and concepts to the interested public.
\end{abstract}

IZA Discussion Papers often represent preliminary work and are circulated to encourage discussion. Citation of such a paper should account for its provisional character. A revised version may be available directly from the author. 


\section{ABSTRACT \\ Do Institutions Affect Social Preferences? Evidence from Divided Korea}

The Cold War division of Korea, regarded as a natural experiment in institutional change, provides a unique opportunity to examine whether institutions affect social preferences. We recruited North Korean refugees and South Korean students to conduct laboratory experiments eliciting social preferences, together with standard surveys measuring subjective attitudes toward political and economic institutions. Our experiments employ widely used dictator and trust games, with four possible group matches between North and South Koreans by informing them of the group identity of their anonymous partners. Experimental behavior and support for institutions differ substantially between and within groups. North Korean refugees prefer more egalitarian distribution in the dictator games than South Korean students, even after controlling for individual characteristics that could be correlated with social preferences; however, two groups show little difference in the trust game, once we control for more egalitarian behavior of North Koreans. North Korean refugees show less support for market economy and democracy than South Korean subjects. Attitudes toward institutions are more strongly associated with the experimental behaviors among South Korean subjects than among North Korean subjects.

JEL Classification: $\quad$ C92, C93, D03, P20

Keywords: social preferences, experiment, institutions, market economy, democracy

Corresponding author:

Jungmin Lee

School of Economics

Sogang University at Seoul

35 Baekbeom-ro, Mapo-gu

Seoul 121-742

KoreaE-mail: junglee@sogang.ac.kr 


\section{Introduction}

Institutions and preferences are central elements in economic analysis in understanding human behavior and economic development. Social scientists have long argued that they interact with each other and co-evolve in the long run, and that it is imperative to figure out the nature of their interactions. In this paper we seek to answer the following questions: Are social preferences endogenous to institutions? If so, how do institutions affect social preferences? Despite its significance, empirical research investigating this issue is inherently subject to the problem of identification since preferences are intertwined with institutions. The citizens of a society select institutions, which in turn define the structure of incentives that constrain the citizens' behavior, and then the citizens may internalize the codes of conduct. Definite answers to our questions would be difficult to give without an exogenous institutional change.

This paper contributes to the investigation of this issue by exploiting the division of Korea into North and South, following the Second World War, and subsequent institutional changes - a gradual progress to market economy and democracy in South Korea and a socialist economy with communist dictatorship in North Korea - that have occurred up to the present. Korea's partition at the 38th parallel can be viewed as an ongoing natural experiment in institutional change (signified as "the Korean experiment" by Acemoglu et al. (2005)); the two Koreas were homogeneous prior to the division, the division was made as a result of the Cold War and independent of ordinary Koreans' preferences, and there has been little mobility and communication between the two populations. Therefore, the case of divided Korea offers a unique opportunity for investigating the long-term impacts of institutional changes over time on individual preferences.

Our empirical approach is to utilize two separate pools of individuals who have lived under different institutions of divided Korea, and to implement with them economic choice experiments eliciting social preferences and standard surveys measuring attitudes toward institutions. Specifically, we recruited two distinct groups of North Koreans, along with South Korean subjects. The first group consists of those who arrived in South Korea within one and a half years prior to our study. We target this group of newly arrived

\footnotetext{
${ }^{1}$ Institutions are broadly defined in the literature as including the codes of conduct and social norms. For example, North (1990) defines institutions as "the rules of game in a society." Roland (2004) distinguishes between fast-moving institutions such as political institutions and slow-moving institutions such as culture and social norms.
} 
refugees since they had little opportunity to experience the South Korean society and they are likely to keep social norms they obtained in North Korea. The second group consists of those who have stayed longer in South Korea, are on average younger than the first group, and were, at the time of the study, students enrolled in universities in South Korea. By design, two groups have different exposures to institutions in North Korea and also to those in South Korea. As a result, we can explore varying lengths of exposures to different institutional regimes to see how differently North Koreans behave. We recruited South Korean (SK) university students as a counterpart group to North Korean (NK) subjects. Thus the second group of NK refugees is more comparable to the SK counterpart.

The experiment employs variants of dictator and trust games that have been widely used in the experimental literature in order to measure various dimensions of social preferences: preferences for giving, trust, and trustworthiness. Specifically, we conducted the following three experiments: $(i)$ the other-other dictator game in which endowment is divided between two anonymous opponents; $(i i)$ the self-other dictator game where endowment is divided between the subject and an anonymous opponent (based on Andreoni and Miller (2002)); and (iii) the trust game (based on Berg et al. (1995)) where the receiver has a chance to return a part of money received from the sender. One important feature of our design is that subjects are informed of the group identity of their partners as NK refugees or SK students. Each subject played the games sequentially against anonymous partners from either the NK or SK groups. This design enables us to measure each dimension of social preferences directed toward in-group and out-group members.

We supplemented our experimental measurement with a large number of survey questions and collected rich information about individual characteristics. The variables common to both Koreans include standard demographic information such as age and gender, and subjective assessments on a variety of socioeconomic affairs. Among them, we are particularly interested in eliciting attitudes toward market economy and democracy. Questions about market economy entail personal attitudes toward private ownership (vs. state ownership), competition, and performance-based incentives. As for democracy, we asked subjects about their attitudes toward a multi-party political system, freedom of voting, and individualism (vs. collectivism).

If we find any differences between SK and NK subjects in our experimental measures of social preferences and if such differences remain significant even after controlling for a 
variety of individual characteristics, it would lend credence to the idea that the experience of living under socialism itself (mainly characterized by central planning and political dictatorship) induces North Korean refugees to have social preferences substantially different from those of South Koreans. In addition, if the heterogeneity of social preferences is related to attitudes toward institutions, it would further support our view that institutions affect preferences of two Koreans. Undoubtedly, North Korean refugees are a selected sample of the North Korean population and have been exposed to South Korean institutions. Despite this legitimate concern, the study with NK refugees may well be justified to investigate the effects of institutions on preferences because it is practically impossible to recruit subjects among those who live currently in North Korea and also the refugeees are likely to be a sample of North Koreans with the most affection to the South Korean society. Therefore, any difference that we find in our paper is likely to be a lower bound for the difference between two Koreas. Obviously the two groups of subjects should differ in many other regards. Thus, we analyzed experimental results by regressing them on group matching dummies along with a set of various individual characteristics and attitudinal variables.

Our main findings are as follows. First, with regard to giving in the dictator game, North Koreans are more egalitarian than South Koreans, irrespective of the group identity of their partner. When we look closely at individual-level behavior, the majority of North Koreans prefer the equal division of money between self and the partner whereas a substantial number of South Koreans are selfish. To highlight the order of the magnitude in differences between North and South, we point out that only $4 \%$ of North Koreans gave zero to their anonymous North Korean counterparts, whereas $30 \%$ of South Koreans gave zero to their South Korean opponents: ${ }^{2}$ North Koreans are significantly more generous relative to the baseline case of South Koreans playing against South Korean partners, even after controlling for individual characteristics as well as experimental controls $3^{3}$ The behavior of South Korean students is quantitatively consistent with the findings in the literature for university students in the United States (e.g., Andreoni and Miller (2002)). In addition, we find that the amount of giving is negatively associated with support for market economy but not with support for democracy. The negative association between

\footnotetext{
${ }^{2}$ These figures are from proportions of "strong" selfish types in Table 5.A.

${ }^{3}$ The difference is substantial and is no less than 9 percentage points in terms of the fraction of money given to other across all specifications of our regression analysis.
} 
preferences for giving and attitudes toward market economy is statistically significant and stronger for South Koreans than for North Koreans.

Second, in the trust game, North Koreans gave more to their partners than South Koreans in both the amount transferred by the first mover and the amount returned by the second mover. However, after controlling for individual characteristics and the share of money sent in the dictator game (following Cox (2004)), there is no significant difference between South and North Koreans about the experimental measures of trust and reciprocity. The trust measure is negatively correlated with support for market economy and positively associated with support for democracy among South Korean subjects. These associations are much weaker for North Korean subjects. Finally, there is no significant relation between reciprocity and attitudes toward institutions.

Third, two different North Korean groups behaved similarly, although they differ substantially by age, education, income prospects, varying exposures to different institutions, and so on. This is consistent with the idea that social preferences are persistent and deeply rooted by institutions..$^{4}$

We contribute to three distinct branches of the literature. First, our paper is directly related to the literature investigating the effects of socialism on individual preferences. Shiller et al. (1992) exploited the collapse of the Soviet Union and East Germany and explored the potential impacts of socialism on individual attitudes. By using surveys over six countries, they found little evidence of the so-called 'Homo-Sovieticus.' In contrast, Alesina and Fuchs-Schündeln (2007), using the survey data from the German Socio-Economic Panel, found that East Germans have stronger preferences for redistribution and state intervention than West Germans about a decade after the German reunification. Our paper advances these studies with the experimental method eliciting social preferences, in addition to the traditional survey method.

Second, more generally, our study adds new evidence to the literature investigating the interaction between institutions and preferences. Tabellini (2008) emphasized the significance of the endogenous interaction between institutions and preferences and their co-evolution in the course of economic development. This implies that institution and preferences are hard to disentangle, making it difficult to identify causality. One subbranch of this literature emphasizes the roles of social preferences, trust among others, in

\footnotetext{
${ }^{4}$ Algan and Cahuc (2013) discuss the malleability of trust and note that trust tends to persist over generations.
} 
the functioning of institutions and the resulting economic performance. See, for example, Putnam (1993), Knack and Keefer (1997), Akerlof and Kranton (2000), Platteau (2000), Aghion et al. (2010), Algan and Cahuc (2010), Bloom et al. (2012), and Algan and Cahuc (2013). Other sub-branch of this literature turns attention to the evolution of individual preferences and the effects of institutions, such as family or market economy, on the formation of social norms. For example, see Hirshman (1982), Bowles (1998), Bisin and Verdier (2001), Alesina and Giuliano (2011), and Benabou and Tirole (2011). In this paper, we exploit the historical division of Korea as a natural experiment of institutional change and therefore can mitigate the endogeneity problem.

Lastly, we contribute to the growing body of the literature investigating determinants and correlates of social preferences. Alesina and Giuliano (2011) discussed determinants of preferences for redistribution and provided empirical evidence using the General Social Survey and the World Values Survey. Other empirical studies in this literature suggested a number of potential correlates of social preferences, including socio-demographic characteristics (Gächter et al., 2004; Fehr et al., 2008), parental background (Bauer et al., 2013), group identity (Fershtman and Gneezy, 2001), the degree of market integration (Henrich et al., 2005), warfare experiences (Whitt and Wilson, 2007; Bauer et al., 2011), political proclivity (Dawes et al., 2012), rule of law (Herrmann et al., 2008), and group activities (Gneezy et al., 2012). Along with this branch of the literature, our paper adds novel evidence on the overall impact of institutional regimes on individuals' social preferences.

The remainder of the paper is organized as follows. Section 2 elaborates the perspective on the division of Korea as a natural experiment in institutional changes. Section 3 describes the design and procedures of the experiment and the survey. Section 4 describes the experimental data and presents the results from regressing experimental measures of social preferences on attitudinal support for market economy and democracy. We conclude in Section 5. This paper also uses Online Appendices to provide the English-translated version of documents used in the experiment and survey, summary information specific to North Korean refugees, and other technical details: $!^{5}$

\footnotetext{
${ }^{5}$ http://www.homepages.ucl.ac.uk/ ${ }^{\sim}$ uctpsc0/Research/KCLLC_OnlineAppendices.pdf
} 


\section{Background: Divided Korea and Refugees}

We have argued that the division of Korea into North and South can be viewed as an ongoing natural experiment in institutional change. We elaborate this argument below.

Homogeneity The population of Korea was homogeneous prior to the division. Korea had remained a unified kingdom for more than 1,200 years between the late 6th century and the early 20th century. The three ruling dynasties over this period - Unified Silla, Goryeo, and Joseon in sequence - occupied basically the same territory, the Korean peninsula. In the early 20th century Japan invaded, annexed, and subsequently ruled Korea until the end of the Second World War. Through all this time, Koreans in the entire territory lived under common political and economic institutions, shared the identical culture, and used the same language. In terms of ethnic and linguistic differences, the Koreas remain two of the most homogeneous nations in the world (Alesina et al., 2003). There was also no large difference in income per capita between southern and northern parts of Korea before its division in 1948 (Lee and Kim, 2011). In this way, before Korea was divided into North and South, both Koreas were homogeneous in a variety of dimensions, including ethnicity, linguistics, culture, status of economy, and political and economic system.

Exogeneity The division of Korea, following the defeat of Japan in the Second World War, was sudden and unintended. Korea was divided as a consequence of the Cold War between the United States (US) and the Union of Soviet Socialist Republics (USSR). The US and the USSR agreed, in the Yalta Conference in February 1945, that their troops would occupy Korea after the Second World War. They neither planned nor desired the territorial and political division of Korea (Hilbert, 2010). The occupation initially occurred along the 38th parallel, with the US occupying the South and the USSR occupying the North. A trusteeship was formed by the US and the USSR for the purpose of establishing a single, independent Korean government in due course. With mistrust growing rapidly between the US and the USSR, the trusteeship failed. The separation along the 38th parallel was then transformed into the division of Korea into North and South with divergent institutions: the Republic of Korea was first established in South Korea in August 1948 and the People's Democratic Republic of Korea was set up soon after in North Korea, with the aid of the US and the USSR respectively (Hilbert, 2010). The process of Korea's division was thus a 
result of the compromise between the two Cold War superpowers, and not determined by Koreans' voluntary choice. In this way, we argue that the historic division of Korea was exogenous, and largely orthogonal to the preferences of ordinary Koreans.

Divergence and persistence The initial adoption of institutions, after the division, was divergent between North Korea and South Korea, and the institutional changes have been persistent over time. South Korea has pursued capitalism with democratic institutions and North Korea has adopted a socialist system with central planning and authoritarian political institutions. The initial adoption of divergent institutions has been reinforced to two polar extremes over time. Over the last six decades, South Korea has pushed an export-oriented market economy, with spectacular economic growth, and its political system has been transformed into mature democracy. North Korea, in contrast, has remained an autarkic socialist economy with disastrous economic failure, intertwined with its authoritarian dynasty as the political system. As a consequence, there is now a huge disparity in income per capita between South and North Korea: in 2005, gross national income per capita in North Korea was estimated to be around 400 US dollars, which is only about $2 \%$ of that of South Korea in the same year (Kim and Lee, 2007). This process of establishing two divergent institutions with stark differences in economic development has obviously affected the identity and mentality of each Korea.

Little contamination Migration between the two Koreas was severely limited before the Korean War in 1950-1953 and became nearly impossible after the war partly because of a heavy military presence on the border. Ordinary Koreans have not been allowed to travel between North and South and have had little opportunity to meet Koreans from the other part. In addition, the two parts are not able to have personal communication in the form of letters, phone calls, etc. North Koreans have suffered the tight state control of information flows and the suppression of information about and from the outside world. Television and radio channels in North Korea are fixed to officially sanctioned North Korean stations. News stories in official radio and television broadcasts obviously reflect official government positions and propaganda in North Korea.$^{6}$ South Koreans are also not permitted to listen

\footnotetext{
${ }^{6}$ North Korea is probably the most repressive regime in the world, with the tight information barrier between its own people and the rest of the world. Nevertheless, that information barrier may be eroding. Lee (2006) and Haggard and Noland (2011) report from surveys with North Korean refugees that residents in some parts of North Korea such as Pyongyang, the capital, watch South Korean television via satellite
} 
to North Korean mass media, without violating their national laws. In this sense, there has been little mobility and a lack of communication between the populations of the two Koreas. Hence, we argue that the two populations are contaminated very little about the institutional changes and the dynamic process of their establishment.

Refugees It is practically impossible to access a representative sample of the general population in North Korea. Instead, we rely on North Korean refugees living in South Korea for our purpose. According to official statistics from the Ministry of Unification in South Korea, the total number of North Korean refugees who have settled in South Korea is about 24,000 as of the end of 2012. Mainly caused by the economic crisis in North Korea since the mid- and late 1990s, the number of NK refugees per year has increased by over 1,000 since 2001. Amid the economic crisis and continuing political repression, North Koreans have been attempting to escape from their country into South Korea or other countries for survival, freedom, or better opportunities for living. Most of the refugees arriving in South Korea initially crossed the border between North Korea and China. Subsequently they left China for other neighboring countries such as Thailand, Laos, Vietnam, Mongolia, and Cambodia through which they were finally sent to South Korea. NK refugees legally have the same rights as South Korean citizens and the South Korean government provides various support for resettlement. However, their adaption to South Korea is challenging partly because of their lack of education and skills necessary for job search in South Korea.

\section{Experimental Design and Survey Details}

\subsection{Samples and procedures}

The experiment and survey were conducted at Seoul National University (SNU) in August and September 2011, called Study 1, and at Sogang University in May 2012, called Study 2. Both universities are located in Seoul, the capital of South Korea. NK subjects in Study 1 are refugees who arrived in South Korea in 2010 and 2011. NK refugees in Study 2 are those who arrived in South Korea earlier and were, at the time of the study, enrolled in a university (most of them from Sogang University; some from other neighboring

dishes. However, they conclude these cases appear atypical. 
universities). In recruiting NK refugees, we relied initially on personal contacts by some key members of the community of NK refugees. After initial contacts, we sent out invitation letters on university letterhead to NK refugees to ensure the credibility of our research and to encourage their voluntary participation in the study. For the group of SK subjects, we recruited undergraduate students at SNU and Sogang University by sending out mass invitation emails through the university IT system, inviting those who were born in South Korea to take part in the experiment. The total number of NK subjects is 205 (133 in Study 1 and 72 in Study 2). The number of SK subjects is 246 (166 in Study 1 and 80 in Study 2).

There were six sessions for each group of NK and SK subjects in Study 1 and three sessions for each in Study 2. The number of subjects in a session varied between 11 and 47 for NK subjects, and between 19 and 34 for SK subjects. Each session consisted broadly of three stages: $(i)$ registration and priming on inter-Korean historical events; $(i i)$ experiment; and (iii) post-experiment survey. Upon arrival of all subjects in a university lecture room, each session started with subjects being asked to read and sign the consent form of the experiment if they wished to participate in the experiment. Once the consent form had been collected, each subject was asked to randomly draw from a box an ID card, on which his or her unique ID number was written. It was emphasized and reiterated throughout the session that subjects should use their unique ID numbers on the registration form, decision sheets in the experiment, and survey questionnaires.

In Study 1, after the random assignment of IDs, NK subjects in each session were randomly divided into three groups. Each group was guided by experiment assistants into another lecture room for registration and priming. Upon arriving in each room, subjects received a registration form asking some confidential information such as contact address and bank account for payments from the experiment. When registration was completed, subjects were invited to answer a short questionnaire about some historic events between South Korea and North Korea. They were informed that their answers were irrelevant to their earnings in the experiment. One group received a set of three questions related to confrontation between SK and NK - the Korean War between 1950 and 1953, the Yeonpyung Island missile assault by North Korea in 2010, and Team Spirit, a joint military training exercise of US and SK forces. This was termed the confrontation priming. Another group was given a set of three questions related to peace-making between SK and NK - the 
First Inter-Korean Summit in 2001, the Gaesung Industrial Complex, and a unified Korean team in a sports event. This was termed the peace-making priming. The third group, called the control group, was given no questions. We introduced the random assignment of such priming to see if reminding such historic inter-Korean events can affect individuals' behavior. For SK subjects in Study 1 and for both NK and SK subjects in Study 2, one session consisted of a single priming treatment.7 After registration and priming on interKorean historical events, all subjects gathered in a large lecture room for the experiment and survey. Subjects were seated with enough distance between them in Study 1 and within cubicles in Study 2 to ensure that there was no communication among them during the experiment and survey. Table 1 gives information on subjects' basic demographics and priming treatments.

\section{- Table 1 here -}

The experiment employs three games in sequence: $(i)$ the other-other dictator game; (ii) the self-other dictator game; and (iii) the trust game. Subjects were informed that the group matching for playing each game would be done about two weeks after the experiment with all participants. They were then invited to make separate decisions in each distinct case of matching, using separate decision tables or sheets. The only information about their opponents that was provided to subjects in Study 1 was either that the opponent is an anonymous NK refugee who entered South Korea in 2010 or 2011 or that the opponent is an anonymous SK student who was born in South Korea and is currently enrolled in a university in Seoul. In Study 2, subjects were only told either that the opponent is an anonymous NK refugee who is currently enrolled in a university in Seoul or that the opponent is an anonymous SK student who was born in South Korea and is currently enrolled in a university in Seoul. We will illustrate the details of the games below. Payments in the experiment were the sum of earnings in each of three games. NK subjects, on average, obtained around 26,000 KRW in both studies. SK subjects, on average, earned 24,000 KRW in Study 1 and 23,000 KRW in Study 2. In addition, as a participation fee, NK subjects received 50,000 KRW in Study 1 and 30,000 KRW in Study 2, and SK

\footnotetext{
${ }^{7}$ The main reason we randomly assigned subjects in a session into three priming treatments for NK subjects in Study 1 was that there was wider variation in the number of subjects across sessions. In order to have a roughly uniform distribution of subjects across treatments and to minimize the potential effects of session size on priming, we adopted this approach.
} 
subjects 10,000 KRW in both studies. Approximately, two weeks after the completion of the study, we transferred payments to the bank accounts for which subjects had given us the details. The subjects were informed of this payment schedule at the very beginning of the experiment 10

After the completion of the experiment, subjects were asked to fill out post-experiment survey questions. The experiment and survey lasted approximately three (two) hours for NK subjects in Study 1 (Study 2) and about one-and-a-half hours for SK subjects in both studies 11

\subsection{Experimental games}

We now describe three games used in the experimental design.

Other-other dictator game In the first experimental task, each subject was asked to allocate 10,000 KRW between two other anonymous participants randomly selected from the entire pool of participants in each study. It was noted that it was not possible to allocate money to him/herself. Given the possibility that each 'other' can be selected from NK or SK subjects, each subject was asked to make a decision for each of three possible matchings: (i) NK vs. NK; (ii) NK vs. SK; and (iii) SK vs. SK. In order to facilitate subjects' decisions, we discretized the set of choices into multiples of $10 \%$ of the initial endowment to be divided between two other participants. The choice problem was presented in a decision table and subjects were asked to tick one column using a pencil ${ }^{12}$

We adopt this other-other allocation task or dictator game for two purposes. First, the social psychology literature (e.g., Turner (1978)) finds that the other-other allocation task,

\footnotetext{
${ }^{8}$ Participation fees were given differently across groups and studies, because of differences in transportation costs and in the length of survey questionnaires.

${ }^{9} 1,200 \mathrm{KRW}$ was exchanged approximately to 1 USD in September 2011.

${ }^{10}$ In order to mitigate any concerns about the credibility of payment methods, subjects were given information about the financial support of this project (from the World Class University Project in the Department of Economics at Seoul National University for Study 1 and from the Department of Economics at Sogang University for Study 2) and contact information for the project director in each study. They were told that if they had any concern about payments, they were free to contact the project director. All payments were made as announced without any problem.

${ }^{11}$ The English-translated version of documents used in the experiment and survey, including instructions and decision sheets, are available in Online Appendix I.

${ }^{12}$ All experiments were done by paper and pencil to avoid any bias arising due to the differential degree of subjects' familiarity with computer.
} 
if followed by a self-other allocation task, can help enhance the sense of group identity (see also Chen and Li (2009)). Second, the complexity of game tasks increases in the sequence of three games. By presenting a simpler game first, we intended to help subjects comprehend the games that followed more easily.

It was publicly announced that each subject's decisions would be used to determine the actual earnings of two other participants and, likewise, that each subject's earnings in this part were determined by decisions made by the other participants in the same study.

Self-other dictator game In the second game, each subject was asked to allocate an endowment between him/herself ( self) and one other participant (other) randomly selected from the pool of participants in each study. We use this game to measure individual preferences for giving and separate them from trust and trustworthiness or reciprocity in the subsequent trust game. For this, we adopted the modified dictator game used by Andreoni and Miller (2002) 13 In this game, subjects were presented with a series of budget sets with varying amounts of initial endowment $m$ and prices for payoffs between self and other, respectively $p_{s}$ and $p_{o}$, satisfying the condition

$$
\pi_{s}+p \pi_{o}=m
$$

where $p$ denotes the relative price of giving, $p_{o} / p_{s}$. The money allocation between self, denoted by $\pi_{s}$, and other, denoted by $\pi_{o}$, should satisfy this budget condition. In the experiment, we used eight different budget sets as shown below:

\begin{tabular}{|l|c|c|c|c|c|c|c|c|}
\hline Budget $(t)$ & 1 & 2 & 3 & 4 & 5 & 6 & 7 & 8 \\
\hline$m_{t}($ KRW $)$ & 10,000 & 15,000 & 15,000 & 18,000 & 25,000 & 30,000 & 30,000 & 36,000 \\
\hline$p_{t}$ & $1 / 3$ & 1 & $1 / 2$ & $1 / 2$ & 1 & 2 & 3 & 2 \\
\hline
\end{tabular}

This design creates rich variations in relative prices and incomes. It allows us to measure preferences for giving at the level of individual subjects.

In order to help subjects make a choice, we present them with a discrete set of possible choices from each budget set as multiples of $10 \%$ transfer of an endowment $m$. Thus, each subject was able to choose $n_{t}$ in the form of money transfer to other in budget set

\footnotetext{
${ }^{13}$ Fisman et al. (2007) utilize a graphical interface that enables them to collect richer, individual-level data to study giving behavior in the modified dictator game.
} 
$t=1, \ldots, 8, n_{t} \times 0.1 \times m_{t}$, for $n_{t}=0,1,2, \ldots, 10$. Subjects were presented with corresponding tables to mark their decisions against each of NK and SK opponents (see Online Appendix I for detail about decision sheets). Earnings in the self-other dictator game were determined in the following way. We randomly formed groups of two subjects. One subject in each group was randomly selected as a decision-maker or dictator. We randomly selected one out of the eight budget sets of the selected decision-maker, corresponding to the identity of the opponent (i.e., against an NK or an SK opponent). Earnings were then determined by the decision in the selected budget set.

Trust game The last game is to measure trust and trustworthiness or reciprocity. We adopted a variant of the trust game used by Berg et al. (1995) in which the first mover allocated an initial endowment of money, 10,000 KRW, between him/herself and the receiver, the second mover. The amount transferred was tripled and the second mover then decided how much of this tripled amount to return to the first mover. By combining the behaviors in the self-other dictator game and the trust game, we can separately identify trust and reciprocity from preferences for giving in the spirit of Cox (2004). Note that the first budget set in the self-other dictator game is equivalent to the decision problem of the first mover in the trust game, except that the second mover has a decision to make in the trust game. Thus, we shall use the giving behavior in the first budget set of the self-other dictator game as a control in measuring trust. We again discretized the set of possible money transfer by the first mover as multiples of $10 \%$ transfer of the endowment 10,000 KRW.

In our experiment, subjects played both roles, i.e., the first mover and the second mover. We used the strategy method by asking the second mover how much he or she was willing to return for each possible amount received. When nothing was transferred by the first mover, there was no decision for the second mover to make. For any positive amount of money transfer (there are 10 possible amounts of money transfer), the second mover was asked to state the amount of money he or she wanted to return. In each role (first mover and second mover), each subject was asked to make decisions for each possible matching, either an NK or an SK opponent.

The earnings in the trust game were determined as follows. We randomly formed groups of two subjects. One in each group was randomly selected as the first mover and the other as the second mover. Having assigned the roles, we matched their corresponding decision 
sheets and determined the earnings of both subjects.

\subsection{Survey}

After the experiments, we conducted a survey to collect information of individual subjects. The common set of questions to NK and SK subjects included demographic information as well as a variety of attitudinal responses such as attitudes toward market economy and democracy, national identity, and trust and trustworthiness attitudes from the General Social Survey (GSS). In addition, NK subjects were asked to fill out questions about political and economic activities in North Korea, experiences of escaping from North Korea prior to entry to South Korea, and the resettlement and assimilation process in South Korea 14

We are particularly interested in finding whether attitudes toward economic and political institutions explain the differences between NK and SK subjects we find from our experiments. To answer the question, we hypothesize that institutional differences between NK and SK are mainly characterized by market economy, regarding economic institutions, and democracy, regarding political institutions, and asked a set of survey questions asking perceptions about market economy and democracy. Attitudinal variable for democracy aggregates the degree of support for $(i)$ a multi-party political system, $(i i)$ freedom of voting, and (iii) individualism (vs. collectivism). Specifically, for a multi-party system, we asked the degree of support for the following sentence: "Multiple political parties are necessary to aggregate diverse opinions." On freedom of voting, the following two sentences were presented: “A nation's leader should be selected among multiple candidates by people's free will" and "I make my own voting decision rather than following others' opinions." As for individualism, "One's liberty can be sacrificed for the benefit of the whole" was presented.

Analogously, we constructed attitudinal variable for market economy by aggregating responses to $(i)$ private ownership (vs. state ownership), (ii) competition, and (iii) performance-based incentives. For private ownership, the following sentence was presented: "It is better for the state rather than individuals to own firms, lands, residences, etc." With regard to competition, we presented subjects with "Competition among individuals is necessary for economic development" and "It is more convenient to live in a collectivist society without competition." Finally, on performance-based incentives, "One should get paid higher

\footnotetext{
${ }^{14}$ Online Appendix II provides summary statistics of variables that are specific to North Korean subjects.
} 
than another, if the former works better than the latter, even though they are of the same age and same rank in the same company" was presented.

These measurements on attitudes toward institutions are subjective but can be quite informative in our case. According to the World Values Surveys conducted in 1989-1992 (that is, the period immediately after the collapse of socialism), residents living in former socialist countries in Eastern Europe appear to prefer stronger government responsibility and less private ownership compared with those living in market economies $\sqrt{15}$ In addition, the comparison between South and North Koreans has an important advantage over such cross-country comparisons: distortions caused by surveying in different languages are unlikely because both Koreans use the same language. Furthermore, answers to questions in connection with market economy and democracy reflect differences in fundamental values between the two systems. South Koreans learn about these values at school and at home, and practice them on various occasions, while North Koreans tend to be indoctrinated with the values of socialism by instruments including review meetings of the Communist Party Lines.

In addition to attitudes toward institutions, because NK and SK subjects are likely to differ in many other regards, we collected information on perception of national identity, attitudes toward NK refugees, trust and trustworthiness attitudes (using questions taken from the General Social Survey), etc. Subjects were asked to report the degree of their support for each of these questions using a five-point scale ranging from strongly disagree to strongly agree. The full detail of attitudinal questions is given in Online Appendix I. In our regression analysis, we will control for a variety of individual characteristics.

We summarize the attitudinal responses of NK and SK subjects in Table 2. When constructing each attitudinal variable in Table 2, we sum a subject's responses to questions, re-ordering them when necessary so that higher scores reflect greater support for that variable. We then normalize the score to generate an attitudinal measure with sample mean 0 and standard deviation 1 . The number in parentheses in the first two columns is a within-group standard error, after the normalization.

\section{- Table 2 here -}

\footnotetext{
${ }^{15}$ The mean of support for government intervention on a scale of 1 (people's responsibility) to 10 (government responsibility) was 5.4 in former socialist countries and 4.9 among the others. Similarly, the mean of support for private ownership on a scale of 1 (private ownership of business) to 10 (government ownership of business) was 4.6 in former socialist countries and 4.4 among the others.
} 
There are notable differences in most attitudinal responses between the two groups. ${ }^{16}$ Above all, NK subjects are in far less support of democracy and market economy than SK subjects. By looking at each component in the attitudinal questions about market economy and democracy, we find that NK subjects show less support for democracy mainly because they show less support for a multi-party system and individualism. There is little difference between NK and SK subjects in the support for voting freedom ${ }^{17}$ On the other hand, NK subjects show less support for each component of market economy. Betweengroup differences are also shown for other attitudinal responses. NK subjects show stronger national identity as Korean and as South Korean, and more positive attitudes toward South Korean society. NK subjects show more compassion toward fellow NK refugees than SK subjects do. There are also between-group variations in attitudinal measures of trust, trustworthiness, being fair, and being helped. NK subjects appear to be more risk averse. For most attitudinal scores, we observe little difference in standard errors between NK and SK groups, suggesting that attitudinal responses within group are equally heterogeneous between the two groups.

\section{Results}

We begin our analysis by describing the experimental data in order to check whether there are any between-group differences in subjects' behavior in the experimental games. The experimental results will quantify the extents to which institutional differences between North and South Korea may impact individual behavior and preferences. We will then move on to the regression analysis to check whether any group differences remain robust after controlling for individual characteristics and experimental controls and to examine the association between experimental measures of social preferences and attitudinal support for market economy and democracy.

\footnotetext{
${ }^{16}$ The NK-SK attitudinal responses remain similar between Study 1 and Study 2. In the interest of brevity, we omit the attitudinal responses for the separate studies.

${ }^{17}$ This is probably because the North Korean authorities claim that their elections are based on freedom of voting.
} 


\subsection{Description of experimental data}

\subsubsection{Preferences for giving}

We first examine the effects of group identity on other-other allocation. In the other-other dictator game, the decision-maker does not receive any direct material compensation from his or her own decision. We intend to see whether there is any in-group or out-group favoritism when subjects' choices have no direct consequence on their own payoffs. Table 3 presents a summary of the percentage of money allocated to the first other opponent in each matching case in the other-other dictator game - NK vs. NK, SK vs. SK, and NK vs. SK ${ }^{18}$ In the asymmetric matching case of NK vs. SK, the first other opponent is an anonymous NK subject. We report the frequencies of allocation decisions to one of three situations: $(i)$ equal division ( $=50 \%)$; $(i i)$ favoritism to the first other opponent $(>50 \%)$; and (iii) favoritism to the second other opponent $(<50 \%)$. In addition, we report the $p$-value for the Wilcoxon rank-sum test to compare the distributions of money allocation by the NK and the SK group in each matching case.

\section{- Table 3 here -}

As evident in Table 3, the equal division of the money is the behavioral norm in the symmetric matching cases for both groups. Across studies and symmetric matching cases, the vast majority (around or more than $75 \%$ ) of subjects allocated equally between two anonymous others. The Wilcoxon rank-sum tests suggest that for each symmetric matching case, the distributions of allocation by the NK and the SK group are not statistically different at the $5 \%$ significance level. On the other hand, the tendency for equal allocation becomes much weaker in the asymmetric matching case, NK vs. SK: only 29\% (Study 1) and $45 \%$ (Study 2) of the SK subjects chose the equal division between an anonymous NK other and an anonymous SK other, while 53\% (Study 1) and 67\% (Study 2) of the NK subjects selected the equal split. A more striking feature is that both NK and SK groups appear to exhibit favoritism toward an anonymous NK opponent rather than an SK opponent. The extent of that favoritism seems stronger in the NK group than in the SK group. However, we cannot reject the null hypothesis that the distributions of allocation

\footnotetext{
${ }^{18}$ We omit the summary description of the data across priming treatments in Table 3 and other tables in this section. We find no systematic effect of priming in any of the three experimental games. In the regression analysis, we use the priming treatments as basic control variables.
} 
by the NK and the SK group are equivalent ( $p$-values are 0.910 in Study 1 and 0.186 in Study 2). Thus, we conclude that there are no group differences in the other-other dictator game.

We next turn to behavior in the self-other dictator game. Unlike in the other-other allocation, subjects in this game choose the division of money between him/herself and an anonymous other opponent. Thus, subjects' behavior in this game reveals their preferences for giving or their degree of generosity. We define the fraction of money given to other as $\pi_{o} /\left(\pi_{s}+\pi_{o}\right)$ in each budget set $\pi_{s}+p \pi_{o}=m$. Table 4 reports the mean fractions of money given to other across budget sets and opponent groups, along with $t$-statistics for pairwise mean differences.

\section{- Table 4 here -}

There are several notable patterns in the subjects' behavior that are informative about the preferences for giving to NK and SK members. First of all, NK subjects, on average, give significantly more to each opponent group than SK subjects do. The pairwise $t$-statistics between NK and SK subjects against each opponent group are reported in columns, (1) - (3) and (2) - (4). Second, SK subjects allocate significantly more to other in each budget set when their opponents are NK subjects than when they are SK subjects (see column (3) - (4) for $t$-statistics). This tendency becomes weaker for the NK subjects and is not significant in six out of the eight budget sets (see column (1) - (2) for $t$-statistics). This may suggest that SK subjects sympathize with the NK group. On the other hand, NK subjects treat NK and SK opponents equally. This may suggest that NK subjects have strong aversion to disparate treatments between groups. Third, the mean fraction given is quite responsive to the relative price of giving for both NK and SK subjects. When the relative price increases (that is, the cost of giving increases), the percentage of money given to other decreases. This suggests overall that our subjects respond sensitively to the change of incentives in the experiment. We highlight the results of the self-other dictator game by presenting graphically the relationship between mean fractions and relative prices of giving for both groups of subjects against each opponent group in Figure 1. ${ }^{19}$

\footnotetext{
${ }^{19}$ One competing hypothesis about the difference between NK and SK behavior is that it is a mere reflection of an income or wealth effect. For this reason, we recruited NK refugees who are enrolled in a university in Study 2. They are more comparable to SK university students in this regard. We find basically no difference in the behavior of NK subjects between Study 1 and Study 2. This seems to suggest that the income or wealth effect is at least not a main driver of the behavioral difference in our data. Furthermore, we are not aware of any empirical evidence that wealth is negatively related to generosity.
} 
The variations in relative price and income enable us to find individual heterogeneity and classify individual behavior into prototypical types of preferences for giving. ${ }^{20}$ Let $U\left(\pi_{s}, \pi_{o} ; \mathcal{M}\right)$ represent a utility function over the distribution of money between self and other, $\left(\pi_{s}, \pi_{o}\right)$, given a matching $\mathcal{M}$. Motivated by Andreoni and Miller (2002), we consider the following four distinct types of preferences for giving: $(i)$ selfish type, $U\left(\pi_{s}, \pi_{o} ; \mathcal{M}\right)=$ $\pi_{s} ;$ (ii) (extreme) altruistic type, $U\left(\pi_{s}, \pi_{o} ; \mathcal{M}\right)=\pi_{o} ;($ iii $)$ Leontief type, $U\left(\pi_{s}, \pi_{o} ; \mathcal{M}\right)=$ $\min \left\{\pi_{s}, \pi_{o}\right\}$; and (iv) perfect substitute type, $U\left(\pi_{s}, \pi_{o} ; \mathcal{M}\right)=\pi_{s}+\pi_{o}$. These four types predict distinctive behaviors in the self-other dictator game. See Online Appendix III for more details. For each individual, we first check whether his or her behavior is consistent with one of these types without noise. In this case, we call it a 'strong' type. For those who cannot be classified without noise, we minimize the Euclidean distance between the observed behavior and the behavior predicted by each preference type and select the one giving the minimum distance. We call this a 'weak' type. The results are reported in Table 5.

\section{- Table 5 here -}

The majority of NK subjects follow the Leontief preference type: $70 \%$ (54\%) against NK opponents and 68\% (56\%) against SK opponents in Study 1 (Study 2, respectively), averaging out to $64 \%$ against NK opponents and $63 \%$ against SK opponents in all samples. The frequencies of preference types do not differ across the group identity of opponents. On the other hand, the major preference type for SK subjects is the selfish one: $43 \%$ (45\%) against NK opponents and 58\% (56\%) against SK opponents in Study 1 (Study 2, respectively), averaging out to $43 \%$ against NK opponents and $57 \%$ against SK opponents in all samples. We observe a higher frequency of the selfish type when SK subjects face SK opponents than when they face NK opponents. It is also notable that some NK subjects are

\footnotetext{
${ }^{20}$ Subjects' behavior in the self-other dictator game shows high compliance to the Generalized Axiom of Revealed Preferences (GARP) for utility maximization hypothesis. We measure the extent of GARP violations, using Afriat's (1972) Critical Cost Efficiency Index (CCEI). The CCEI is defined to be between zero and one; the closer the CCEI is to one, the closer the data are to satisfying GARP. The average CCEI scores for SK subjects are 0.998 in both cases against NK and SK opponents. For NK subjects, the average CCEI scores are 0.970 when facing NK opponents and 0.973 when playing against SK opponents. Varian (1991) suggests a threshold of 0.95 for determining whether individual behavior is close enough to satisfying GARP.
} 
altruistic while virtually none of SK subjects are so. Overall, the distributions of preference types confirm the aggregate behavior of NK and SK subjects.

A couple of remarks are in order before we move to behavior in the trust game. First, we point out that the behavior of the SK subjects is largely consistent with the findings in the literature with university students in the US. Andreoni and Miller (2002) reported that their subjects gave away around $23 \%$ of the endowment when the relative price of giving was 1. Fisman et al. (2005), using more variations of relative price, reported that their subjects gave about $19 \%$ of money to other over all prices. Forsythe et al. (1994) found similar evidence on giving behavior. In our experimental data, when the relative price of giving was 1 , the SK subjects gave around $21 \%$ and $19 \%$ of the endowment to their fellow SK subjects in Study 1 and Study 2, respectively. Over all prices, our SK subjects gave around $21 \%$ of money to their in-group members in both studies. Second, in the individual-level analysis, Andreoni and Miller (2002) reported that the majority of their subjects (around 47\%) behaved closest to the selfish preference type. Therefore, we conclude that the behavior of SK subjects against SK opponents in our experiment is consistent with the findings in the literature. We take the case of SK against SK as a baseline case in the subsequent regression analysis.

\subsubsection{Trust and reciprocity}

Table 6 summarizes the behaviors of the first mover and the second mover in the trust game. Panel A reports the average fraction transferred (relative to the endowment) by the first mover across studies and groups. We also report values of $t$-statistics comparing sample means between when NK is an opponent and when SK is an opponent. First, the average fractions of money transferred are quite high, ranging between 0.25 and 0.43 . It appears that the NK group transfers more than the SK group in each study. When we look at the within-study, within-group difference between NK opponent and SK opponent, the NK subjects transferred the same amount regardless the identity of opponents. However, the SK subjects transferred significantly more to NK opponents than to SK opponents.

\section{- Table 6 here -}

Panel B of Table 6 presents the average fraction of money returned (relative to the money available) by the second mover. Again we report $t$-test results from comparing 
means between when the opponent is NK and when the opponent is SK. First, with regard to the average fraction of money returned, we find similar patterns of behavior to those in the dictator game: the NK subjects return more than the SK subjects and the NK subjects do not discriminate between NK and SK opponents, whereas the SK subjects return more when they face NK opponents than when they face SK opponents.

The literature of the trust game (e.g., Berg et al. (1995), Glaeser et al. (2000), Fehr et al. (2003), and Karlan (2005)) typically refers to the amount sent by the first mover as a measure of trust and to the amount returned by the second mover as a measure of trustworthiness or reciprocity. However, the amounts sent and returned in the trust game are likely driven also by preferences for giving which are evidenced in the self-other dictator game. Hence, it is more plausible to differentiate trust and reciprocity from preferences for giving and measure them separately. In the regression analysis in Section 4.2, we shall control for preferences for giving in comparing trust behavior across and within groups, in the spirit of Cox (2004) and Sapienza et al. (2007). To this end, we highlight again that the decision problem in the first budget set of the self-other dictator game is the same as the first mover's problem in the trust game, except that the second mover will make a decision in response to the first mover's decision. We shall use the fraction of money given in this problem of the self-other dictator game as a control for preferences for giving.

For the discussion on the measurement of reciprocity from the second mover's behavior, let us denote by $\left(m_{s}, m_{o}\right)$ the distribution of money given in the first mover's decision, from the second mover's perspective. Let $\left(\pi_{s}, \pi_{o}\right)$ denote the receiver's choice satisfying the budget constraint $\pi_{s}+\pi_{o}=m_{s}$. The second mover's preferences can be represented by a utility function, $u\left(\left(\pi_{s}, \pi_{o}\right),\left(m_{s}, m_{o}\right), I_{T G}\right)$, where $I_{T G}$ is an indicator of the trust game, summarizing all other relevant information such as the fact that $\left(m_{s}, m_{o}\right)$ is given by the sender's decision. For the purpose of comparison, $I_{T G}=0$ means that $\left(m_{s}, m_{o}\right)$ is exogenously given (by an experimenter), representing the situation of the dictator game. We assume that subjects choose $\left(\pi_{s}^{I_{T G}}, \pi_{o}^{I_{T G}}\right)$ to maximize such underlying preferences. Unfortunately, we do not have comparable $\left(m_{s}, m_{o}\right)$ from both dictator and trust games in our data. Nevertheless, our design generates comparable cases under the following restriction on the utility function: $u\left(\left(\pi_{s}, \pi_{o}\right), m_{s}-m_{o}, I_{T G}\right)$. This implies that the individual is concerned only about the difference in money distribution between self and other, $m_{s}-m_{o}$, rather than the distribution itself, $\left(m_{s}, m_{o}\right)$. 
The self-other dictator game has $m_{s}-m_{0}=15,000$ and 25,000 when the relative price of giving is 1 . Among the situations faced by the receiver in the trust game, the closest to $m_{s}-m_{0}=15,000$ and 25, 000 (within 10,000) are $\left(m_{s}, m_{o}\right)=(18,000,4,000)$ and $(27,000,1,000)$, respectively. For the purpose of controlling for preferences for giving in measuring reciprocity, we shall utilize only these two decision situations of the second mover in the trust game in our later regression analysis.

\subsection{Regression results}

The main interests in our regression analysis lie in $(i)$ examining whether the between-group differences in experimental behavior remain robust after controlling for a variety of potentially confounding factors and (ii) exploring the relationships between social preferences and attitudinal support for market economy and democracy. In the regression analysis, we employ three matching dummies to facilitate between-group comparisons: $N K$ denotes a dummy variable indicating whether a decision-maker (e.g., self in the self-other dictator game) is an NK subject; NKr represents a dummy indicating whether a recipient (e.g., other in the self-other dictator game) is an NK opponent; and $N K \times N K r$ denotes a dummy indicating that an NK subject faces an NK opponent. The baseline case of matching is thus the case where an SK subject plays against an SK opponent ${ }^{21}$

\subsubsection{Preferences for giving}

Table 7 presents the regression results about giving behavior in the self-other dictator game ${ }^{22}$ Each individual subject made 16 decisions over two different opponent groups (eight decisions for each of NK and SK opponent groups). We use the fraction of money given to other, $\pi_{o} /\left(\pi_{s}+\pi_{o}\right)$, as the dependent variable. Robust standard errors, clustered by individual subject, are reported in parentheses.

\section{- Table 7 here -}

\footnotetext{
${ }^{21}$ The data contain four possible pairs. They match to the following combinations of the dummy variables: (i) $N K=0, N K r=0$, and $N K \times N K r=0$ when an SK subject plays against an SK opponent; (ii) $N K=0, N K r=1$, and $N K \times N K r=0$ when SK against NK; (iii) $N K=1, N K r=0$, and $N K \times N K r=0$ when NK against SK; and (iv) $N K=1, N K r=1$, and $N K \times N K r=1$ when NK against NK.

${ }^{22}$ Online Appendix IV contains the full description of regression results in this section.
} 
The simplest specification (column 1) uses only demographic variables (gender, four categories of age, and their interactions with the $N K$ dummy) and experimental controls (the matching dummies, priming treatments, the natural logarithm of amounts of endowment, the relative price of giving, a dummy for Study 1, and the number of each session's participants). We first note that priming on inter-Korean historical events has no effects on giving behavior. This might be in part because our priming treatments are not strong enough to stimulate subjects or in part because their existing notion about the NK-SK relationship is too firm to manipulate.

The coefficients on the matching dummies confirm the differences in giving behavior across groups established in the previous section. Compared with the baseline case of SK against SK, NK subjects give 19 percentage points more to SK opponents, SK subjects give around 8 percentage points more to NK opponents, and NK subjects give 20 percentage points more to NK opponents.

Column 2 reports the correlation between giving behavior and attitudinal support for market economy and democracy, controlling only for the demographic information and the experimental controls. We find that attitudinal support for market economy is negatively correlated with giving behavior, while there is no significant relation between attitudes toward democracy and giving behavior: a standard deviation increase in attitudinal score for market economy is associated with a decrease of 3 percentage points in giving behavior. This is statistically significant at the $1 \%$ significance level. We also find that the coefficient on the NK matching dummy decreases a bit: NK subjects give 16 percentage points more to SK subjects relative to the case of SK against SK. Other coefficients on the matching dummies change little.

In column 3, we add to the list of controls other attitudinal variables such as national identities, attitudes toward NK refugees, and trust/trustworthiness attitudes. First, the coefficient on the NK matching dummy drops substantially, meaning that NK subjects give only around 9 percentage points more to SK opponents than SK subjects do. There is little change in the other coefficients of matching dummies. Second, the association between the attitudinal score for market economy and giving behavior is robust to the addition of other attitudinal responses in the regression analysis. Overall, the between-group variations in other attitudinal variables explain around half of the NK-SK difference in giving behavior when facing SK opponents. However, the variations in other attitudinal variables are not 
able to explain the relation between giving behavior and support for market economy.

Columns 4 and 5 decompose the relation between giving behavior and support for institutions by interacting these attitudinal scores with matching dummies, based on the specifications of columns 2 and 3, respectively. This decomposition exercise is informative and demonstrates the group differences in the association of giving behavior to support for market economy. The highest correlations come from SK subjects. Both specifications suggest that the negative association between giving behavior and the attitudinal score for market economy is strongest in the case of SK subjects facing NK opponents and next strongest when SK subjects play against SK opponents. From the results in column 5, a standard deviation increase in attitudinal score for market economy is associated with a decrease in amount given of more than 6 percentage points in the case of SK against NK and of about 4 percentage points in the case of SK against SK. These associations are weak for NK subjects: a standard deviation increase in score for market economy is associated with a decrease in amount given of around 2.3 percentage points in the case of NK against NK and of around 0.2 percentage point in the case of NK against SK.

Finally, column 6 includes all the previous controls - the demographic information, experimental controls, and attitudinal controls - as well as the interactions of other attitudinal controls with matching dummies. The negative correlation between giving behavior and attitudinal support for market economy is robust to all these controls. ${ }^{23}$ The difference in giving behavior reduces to around 9 percentage points between NK and SK subjects facing SK opponents but remains significant.

The group differences in giving behavior and their associations with attitudinal support for institutions are graphically presented in Figure 2. For this purpose, we take the regression results in column 6 with the full set of controls to predict giving behavior. We normalize this predicted value to be zero for the baseline case of SK against SK with its corresponding attitudinal score for market economy or democracy being zero. Each panel presents the predicted values of giving as a money fraction in each of the four matching cases: NK against NK, NK against SK, SK against NK, and SK against SK. They are computed conditional on the attitudinal score of interest being either -1 or 1 . Panel A shows that relative to the baseline case of SK against SK, predicted giving in each of other

\footnotetext{
${ }^{23}$ We conducted the same regression analysis with each separate sample of South Korean and North Korean subjects, as presented in Online Appendix IV. The associations between giving behavior and support for market economy remain largely unchanged for each group.
} 
three matching cases is higher on average by around 10 percentage points. Because SK subjects' behavior is sensitively associated with the score for market economy, when the attitudinal score for market economy increases by two standard deviations (from -1 to 1), this predicted value of giving drops by around 12 percentage points in the case of SK against NK and by about 8 percentage points in the case of SK against SK (demonstrated by the slope of the line segment in each matching case in the figure). In contrast, as noted in Table 7, for all matching cases, average giving behavior does not respond sensitively to the change in attitudinal support for democracy.

- Figure 2 here -

\subsubsection{Trust and reciprocity}

Table 8 reports the regression analysis of trust behavior (the behavior of the first mover in the trust game) on the set of controls. Robust standard errors, clustered by individual subject, are reported in parentheses.

\section{- Table 8 here -}

Column 1 presents the baseline result by controlling for the demographic information and the experimental controls including the matching dummies. In addition, as discussed in the previous section, the fraction of money (relative to the amount of endowment) given in the self-other dictator game is added for the control of preferences for giving. We first find strong evidence that the first mover's behavior is significantly driven by preferences for giving, confirming Cox (2004). Controlling for this, there is no significant difference in the experimental measure of trust between NK and SK subjects against SK opponents (0.1\% difference). NK subjects transfer around 0.8 percentage point less to NK opponents relative to the baseline case of SK against SK. SK subjects transfer 3.4 percentage points more money to NK opponents than to SK opponents. This is statistically significant at the $10 \%$ significance level. We find that priming on inter-Korean historical events does not affect subjects in the trust game.

Column 2 adds the attitudinal score for market economy and democracy, in addition to the baseline controls used in the first specification. Column 3 further adds other attitudinal variables. There is little change in the coefficients on the matching dummies. Interestingly, the trust measure is negatively correlated with attitudinal support for market economy and 
positively related to attitudinal support for democracy: a standard deviation increase in attitudinal score for market economy (for democracy) is associated with around a decrease of 4 percentage points (an increase of 3 percentage points, respectively) in the transferred amount. This correlation has little to do with the variations in other attitudinal responses.

Columns 4 and 5 decompose the relation between the experimentally measured trust and attitudinal support for institutions by interacting these attitudinal scores with the matching dummies. Again the highest correlations between these are produced by SK subjects. Both specifications suggest that the negative association between trust and attitudinal score for market economy is strong and significant to SK subjects regardless of the identity of opponents: a standard deviation increase in attitudinal support for market economy is associated with a decrease of 6 or 7 percentage points in the transferred amount after controlling for giving preferences. This is statistically significant at the $1 \%$ level of significance. The relation between trust and score for market economy is rather weak and insignificant for NK subjects: a standard deviation increase in score for market economy is associated with an increase of 0.4 percentage point in the transferred amount in the case of NK against SK and around a decrease of 1.5 percentage point in the case of NK against NK. Similarly, the positive association between trust and attitudinal score for democracy applies significantly to SK subjects: a standard deviation increase in support for democracy is associated with around an increase of 5 (4.5) percentage points in the experimental measure of trust in the case against NK opponents (SK opponents, respectively). This is statistically significant at the $5 \%$ level of significance. We find much weaker and insignificant associations between them for NK subjects. ${ }^{24}$

Column 6 reports the regression result with the full set of controls including the interactions of other attitudinal scores with matching dummies. With all the controls, there is no significant difference in trust across groups. Intriguingly, we find that the relation between trust and attitudinal support for market economy and democracy is robust to the controls we use. For the sake of illustration, we graphically present the predicted value of trust in each matching case, conditional on the attitudinal score of interest being -1 or 1, in Figure 3. We again normalize this predicted value to be zero for the baseline case of SK against SK with its corresponding attitudinal score for market economy or democracy

\footnotetext{
${ }^{24} \mathrm{We}$ again conducted the same regression analysis of behavior in the trust game for each separate sample of North Korean and South Korean subjects. The associations between trust behavior and support for institutions remain unchanged for each group, as reported in Online Appendix IV.
} 
being zero. Both panels clearly show that the average predicted values of trust are no different across all matching cases and that the association between the trust measure and the attitudinal score for market economy or democracy is strong for SK subjects but not for NK subjects.

\section{- Figure 3 here -}

We next turn to the analysis of reciprocity using the behavior of the second mover in the trust game. Table 9 presents the regression results of the money fraction returned on various controls. As we discussed earlier, we use two decisions by the second mover, where the amount of money available is either 18,000 or 27,000 KRW, and match corresponding similar decisions in the self-other dictator game to control for preferences for giving. Robust standard errors, clustered by individual subject, are reported in parentheses.

\section{- Table 9 here -}

The baseline result reported in column 1 is obtained by controlling for the demographic information and the experimental controls, as well as the money fractions in the decisions of the self-other dictator game as a control for preferences for giving. We also add an indicator for the second mover having 27,000 KRW available. Similar to the trust behavior, the second mover's behavior is significantly related to their giving behavior in the dictator game. After controlling for preferences for giving, we find no difference in the reciprocity measure across groups. With regard to priming effects, subjects in the priming treatment of peace-making appear to have lower reciprocity than those in the control treatment with no priming, in some specifications. However, the results are not robust across different specifications.

We follow the same steps of controlling for extra survey information as in the analysis of giving and trust behavior. We find no significant effects of matching dummies across different specifications, suggesting that there is no group difference in reciprocity. Also, the relation between reciprocity and attitudinal support for market economy and democracy is quite weak and not significant in most cases. Relative to the baseline matching case of SK against SK, there is some association between reciprocity and attitudinal support for democracy when SK subjects face NK opponents. It is significant at the $10 \%$ significance level but the magnitude is small. Therefore, we conclude that the experimental measure 
of reciprocity is no different between NK and SK subjects and has little associations with attitudinal support for market economy and democracy.

\section{Conclusion}

We have examined whether institutions affect social preferences by exploiting the division of Korea as a natural experiment of institutional change. Using North Korean refugees and South Korean students, we have provided new evidence on the effects of institutions on social preferences. We employed widely-used experiments to elicit social preferences and standard surveys to measure various aspects of individual characteristics as well as subjective attitudes toward economic and political institutions. The two Koreas are different in many institutional details. We have focused on market economy, as a key difference in economic institutions, and democracy, as a key difference in political institutions.

North Korean subjects exhibit more egalitarian behavior in the dictator game, compared with South Korean subjects in our sample. Even after controlling for a rich set of confounding factors, we find that the inter-Korean differences in preferences for giving remain robust. However there is no significant group difference in trust or reciprocity, after controlling for preferences for giving. NK subjects exhibit significantly less support for market economy and democracy. Preferences for giving and trust are negatively associated with attitudinal support for market economy. That is, those who are in more favor of market economy are more likely to be self-regarding and less likely to trust an anonymous person. Trust is positively correlated with support for democracy. Those who are in more favor of democracy are more likely to trust an anonymous person. These associations are strong and significant among South Korean subjects but rather weak and often insignificant among North Korean subjects. It is beyond the scope of this paper but an interesting topic for further research to explain why subjective attitudes toward market economy and democracy did not translate into the behavior in the experiments for North Koreans.

The adaption of North Korean refugees in South Korea presents a significant challenge. They often lack the education and skills that are useful in searching for a job. Our study supports the view that, in addition to lack of appropriate skills, they arrive with different social norms and preferences. Are these differences important for the process of assimilation into the South Korean society? Do social preferences change over time and, if so, how do 
they change? Understanding the evolution of social preferences is an important avenue for future research.

Acknowledgement We thank Christian Dustmann, Andreas Leibbrandt, John A. List, Imran Rasul, and Gérald Roland for helpful comments and suggestions. The paper has also benefited from suggestions by participants in various conferences and seminars. We are grateful to Sunju Hwang, Joonhwi Joo, Seungho Jung, Jongwook Kim, Joonhyung Kim, Minjung Kim, Myeong Sung Kim, Nathalie Kim, Nayoung Kim, Olivia Kim, Seoyoung Kim, Wooyoung Kim, Min Jin Kwon, So Hyun Nam, Youngkwang Lee, Yonghyun Nam, Narae Oh, Choong Kwon Park, Hyeyeon Park, Hyunmin Park, Joontae Park, Sora Park, Jinseok Shin, and Daehoon Sung for their excellent research assistance. Byung-Yeon Kim acknowledges that this work was supported by grant R32-2009-000-20055-0 from the World Class University (WCU) project of the Korean Ministry of Education, Science \& Technology (MEST) and the National Research Foundation of Korea (NRF) through Seoul National University. Sokbae Lee thanks European Research Council for the grant ERC2009-StG-240910-ROMETA.

\section{References}

[1] Acemoglu, Daron, Simon Johnson, and James A. Robinson (2005), "Institutions as the Fundamental Cause of Long-Run Growth," In: Aghion, P. and S. Durlauf (eds.), Handbook of Economic Growth. North Holland.

[2] Afriat, Sydney N. (1972), "Efficiency Estimates of Production Functions," International Economic Review, 13(3), 568-598.

[3] Aghion, Philippe, Yann Algan, Pierre Cahuc, and Andrei Shleifer (2010), "Regulation and Distrust," Quarterly Journal of Economics, 125, 1015-1049.

[4] Akerlof, George A. and Rachel E. Kranton (2000), "Economics and Identity," Quarterly Journal of Economics, 115(3), 715-753.

[5] Alesina, Alberto, Arnaud Devleeschauwer, William Easterly, Sergio Kurlat, and Romain Wacziarg (2003), "Fractionalization," Journal of Economic Growth, 8(2), 155194. 
[6] Alesina, Alberto and Nicola Fuchs-Schündeln (2007), "Goodbye Lenin (or Not?): The Effect of Communism on People," American Economic Review, 97(4): 1507-1528.

[7] Alesina, Alberto and Paola Giuliano (2011), "Preferences for Redistribution," In: Bisin, A. and J. Benhabib (eds.), Handbook of Social Economics. North Holland.

[8] Algan, Yann and Pierre Cahuc (2010), "Inherited Trust and Growth," American Economic Review, 100(5), 2060-2092.

[9] Algan, Yann and Pierre Cahuc (2013), "Trust, Growth and Well-being: New Evidence and Policy Implications," IZA Discussion Paper 7464.

[10] Andreoni, James and John H. Miller (2002), "Giving According to GARP: An Experimental Test of the Consistency of Preferences for Altruism," Econometrica, 70(2), 737-757.

[11] Bauer, Michal, Alessandra Cassar, Julie Chytilová, and Joseph Henrich (2011), "War's Enduring Effects on the Development of Egalitarian Motivations and Ingroup Biases," mimeo, CERGE-EI.

[12] Bauer, Michal, Julie Chytilová, and Barbara Pertold-Gebicka (2013), "Parental Background and Other-Regarding Preferences in Children," Experimental Economics, 1-23.

[13] Benabou, Roland and Jean Tirole (2011), "Laws and Norms," NBER Working Paper 17579.

[14] Berg, Joyce, John Dickhaut, and Kevin McCabe (1995), "Trust, Reciprocity, and Social History," Games and Economic Behavior, 10(1), 122-142.

[15] Bisin, Alberto and Thierry Verdier (2001), "The Economics of Cultural Transmission and the Dynamics of Preferences," Journal of Economic Theory, 97(2), 298-319.

[16] Bloom, Nicholas, Raffaella Sadun, and John Van Reenan (2012), "The Organizations of Firms Across Countries," Quarterly Journal of Economics, 127(4), 1663-1705.

[17] Bowles, Samuel (1998), "Endogenous Preferences: The Cultural Consequences of Markets and Other Economic Institutions," Journal of Economic Literature, 36(1), 75-111.

[18] Chen, Yan and Sherry X. Li (2009), "Group Identity and Social Preferences," American Economic Review, 99(1), 431-457. 
[19] Cox, James C. (2004), "How to Identify Trust and Reciprocity," Games and Economic Behavior, 46, 260-281.

[20] Dawes, Christopher T., Magnus Johannesson, Erik Lindqvist, Peter Loewen, Robert Ostling, Marianne Bonde, and Frida Priks (2012), "Generosity and Political Preferences," IFN Working Paper 941, Research Institute of Industrial Economics, Stockholm.

[21] Fehr, Ernst, Helen Bernhard, and Bettina Rockenbach (2008), "Egalitarianism in Young Children," Nature, 454(28), 1079-1084.

[22] Fehr, Ernst, Urs Fischbacher, Bernhard von Rosenbladt, Jürgen Schupp, and Gert Wagner (2003), "A Nation-Wide Laboratory: Examining Trust and Trustworthiness by Integrating Behavioral Experiments into Representative Surveys," CESifo Working Paper 866.

[23] Fershtman, Chaim and Uri Gneezy (2001), "Discrimination in a Segmented Society: An Experimental Approach," Quarterly Journal of Economics, 116(1), 351-377.

[24] Fisman, Raymond, Shachar Kariv, and Daniel Markovits (2005), "Individual Preferences for Giving," mimeo.

[25] Fisman, Raymond, Shachar Kariv, and Daniel Markovits (2007), "Individual Preferences for Giving," American Economic Review, 97(5), 1858-1876.

[26] Forsythe, Robert, Joel Horowitz, N. E. Savin, and Martin Sefton (1994), "Fairness in Simple Bargaining Games," Games and Economic Behavior, 6(3), 347-369.

[27] Gächter, Simon, Benedikt Herrmann, and Christian Thöni (2004), "Trust, Voluntary Cooperation, and Socio-Economic Background: Survey and Experimental Evidence," Journal of Economic Behavior and Organization, 55(4), 505-531.

[28] Glaeser, Edward, David Laibson, Jose Scheinkman, and Christine Soutter (2000), "Measuring Trust," Quarterly Journal of Economics, 115(3), 811-846.

[29] Gneezy, Uri, Andreas Leibbrandt, and John A. List (2012), "Ode to the Sea: On the Emergence of Social Norms," mimeo.

[30] Haggard, Stephen and Marcus Noland (2011), Witness to Transformation: Refugee Insights into North Korea. Peterson Institute for International Economics. 
[31] Henrich, Joseph, Robert Boyd, Samuel Bowles, Colin Camerer, Ernst Fehr, Herbert Gintis, Richard McElreath, Michael Alvard, Abgail Barr, Jean Ensminger, Natalie Smith Henrich, Kim Hill, Francisco Gil-White, Michael Gurven, Frank W. Marlowe, John Q. Patton, and David Tracer (2005), "Economic Man' in Cross-cultural Perspective: Behavioral Experiments in 15 Small-Scale Societies," Behavioral and Brain Sciences, 28(6), 795-815.

[32] Herrmann, Benedikt, Christian Thöni, and Simon Gächter (2008), "Antisocial Punishment Across Societies," Science, 319, 1362-1367.

[33] Hilbert, Hanns G. (2010), "A Comparison of German and Korean Division: Analogies and Differences," International Journal of Korean Unification Studies, 19(1), 126-156.

[34] Hirshman, Albert O. (1982), "Rival Interpretations of Market Society: Civilizing, Destructive, or Feeble?" Journal of Economic Literature, 20(4), 1463-1484.

[35] Karlan, Dean (2005), "Using Experimental Economics to Measure Social Capital and Predict Financial Decisions,” American Economic Review, 95(5), 1688-1699.

[36] Kim, Byung-Yeon and Suk Lee, (2007), "Measuring North Korea's GNI," Report to Ministry of Unification of Republic of Korea (in Korean).

[37] Knack, Stephen and Philip Keefer (1997), "Does Social Capital Have an Economic Payoff? A Cross-Country Investigation," Quarterly Journal of Economics, 112(4), 1251-1288.

[38] Lee, Ki-Young (2006), "Significant Factors Associated with Labor Market Activities and Self-Sufficiency among North Korean Refugee Migrants," The Korean Journal of Unification Affairs, 18(1), 179-216 (in Korean).

[39] Lee, Suk and Doeol Kim, (2011), "The Comparison of Long-Term Economic Statistics between South Korea and North Korea and Implications for North Korean Policies," KDI Series of Policy Studies (in Korean).

[40] North, Douglas C. (1990), Institutions, Institutional Change, and Economic Performance. Cambridge University Press.

[41] Platteau, Jean-Phillipe (2000), Institutions, Social Norms, and Economic Development. Academic Publishers. 
[42] Putnam, Robert (1993). Making Democracy Work: Civic Traditions in Modern Italy. Princeton University Press.

[43] Roland, Gérald (2004), "Understanding Institutional Change: Fast-Moving and SlowMoving Institutions," Studies in Comparative International Development, 38(4), 109131.

[44] Sapienza, Paola, Anna Toldra, and Luigi Zingales (2007), "Understanding Trust," NBER Working Paper 13387.

[45] Shiller, Robert J., Maxim Boycko, Vladimir Korobov, Sidney G. Winter, and Thomas Schelling (1992), "Hunting for Homo Sovieticus: Situational versus Attitudinal Factors in Economic Behavior," Brookings Papers on Economic Activity, 1992(1), 127-194.

[46] Tabellini, Guido (2008), "Institutions and Culture," Journal of the European Economic Association, 6(2-3), 255-294.

[47] Turner, John C. (1978), "Social Categorization and Social Discrimination in the Minimal Group Paradigm," In: Tajfel, H. (ed.), Differntiation between Social Groups. Academic Press.

[48] Varian, Hal R. (1991), "Goodness of Fit for the Revealed Preference Tests," mimeo.

[49] Whitt, Sam and Rick K. Wilson (2007), "The Dictator Game, Fairness and Ethnicity in Postwar Bosnia," American Journal of Political Science, 51(3), 655-668. 
Figure 1. Money fraction given and relative price of giving in the self-other dictator game

\section{A. Study 1}

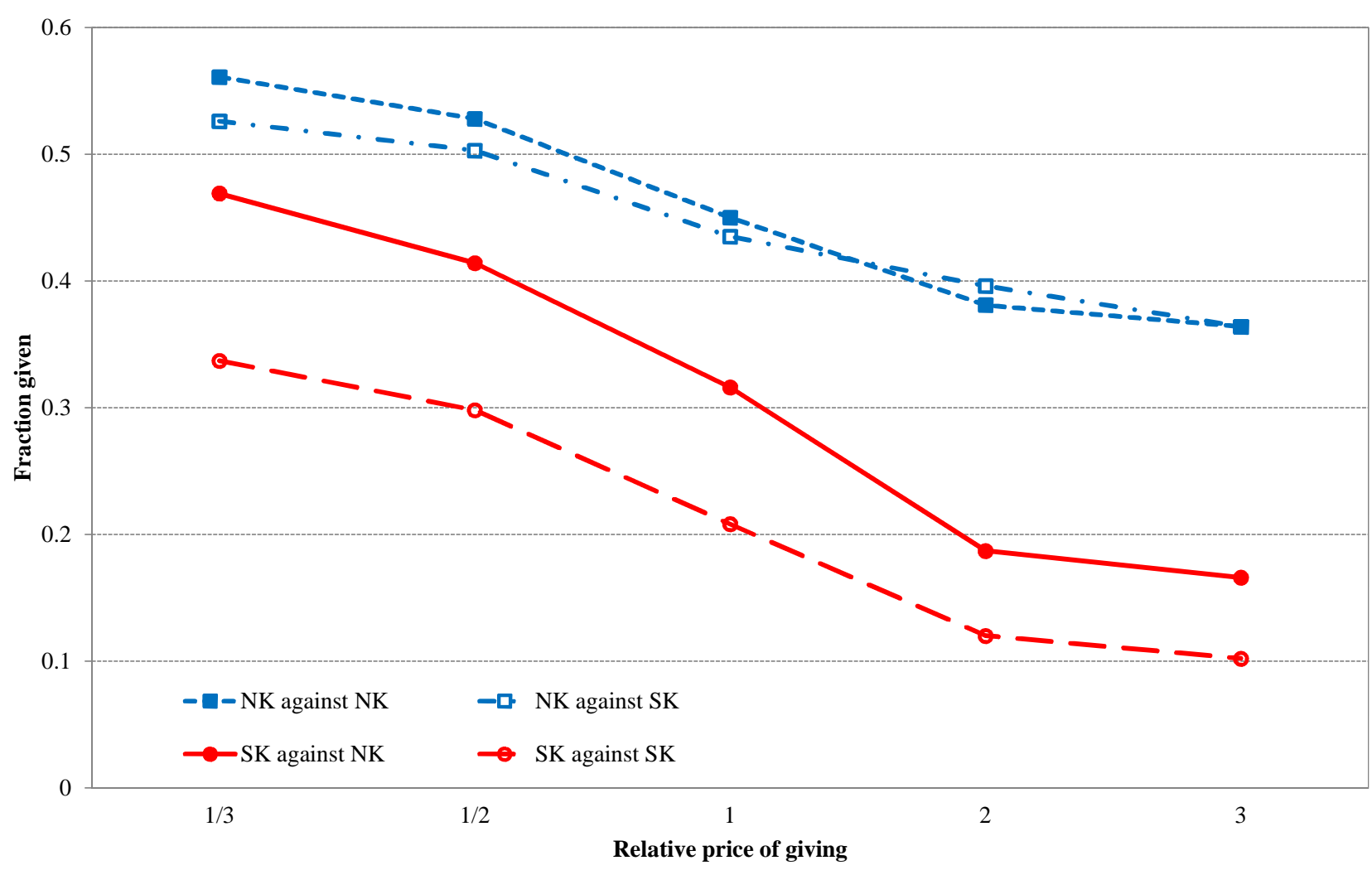

B. Study 2

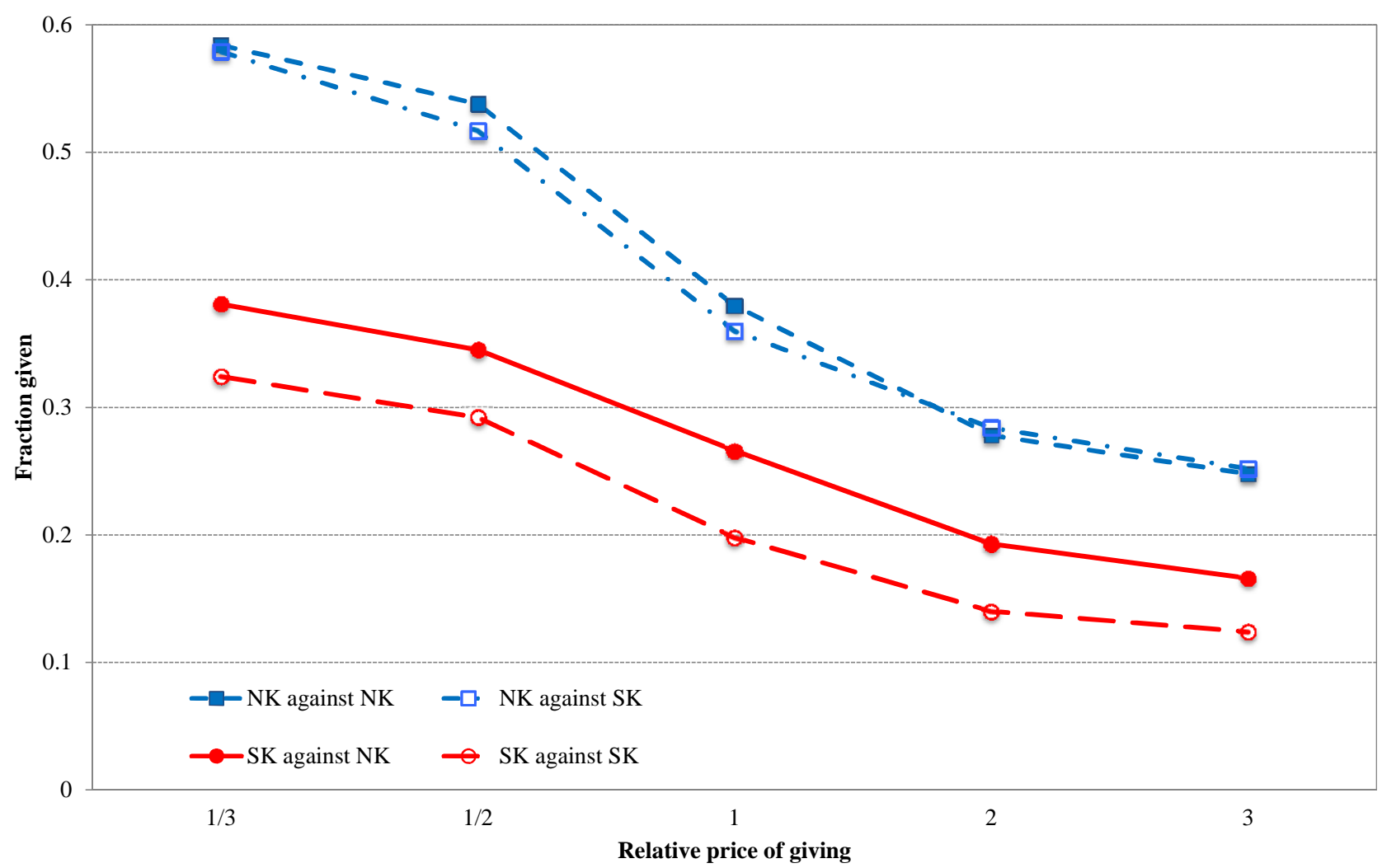


Figure 2. Predicted giving behavior conditional on attitudes toward market economy and democracy

A. Score of attitudes toward market economy $=-1$ and 1

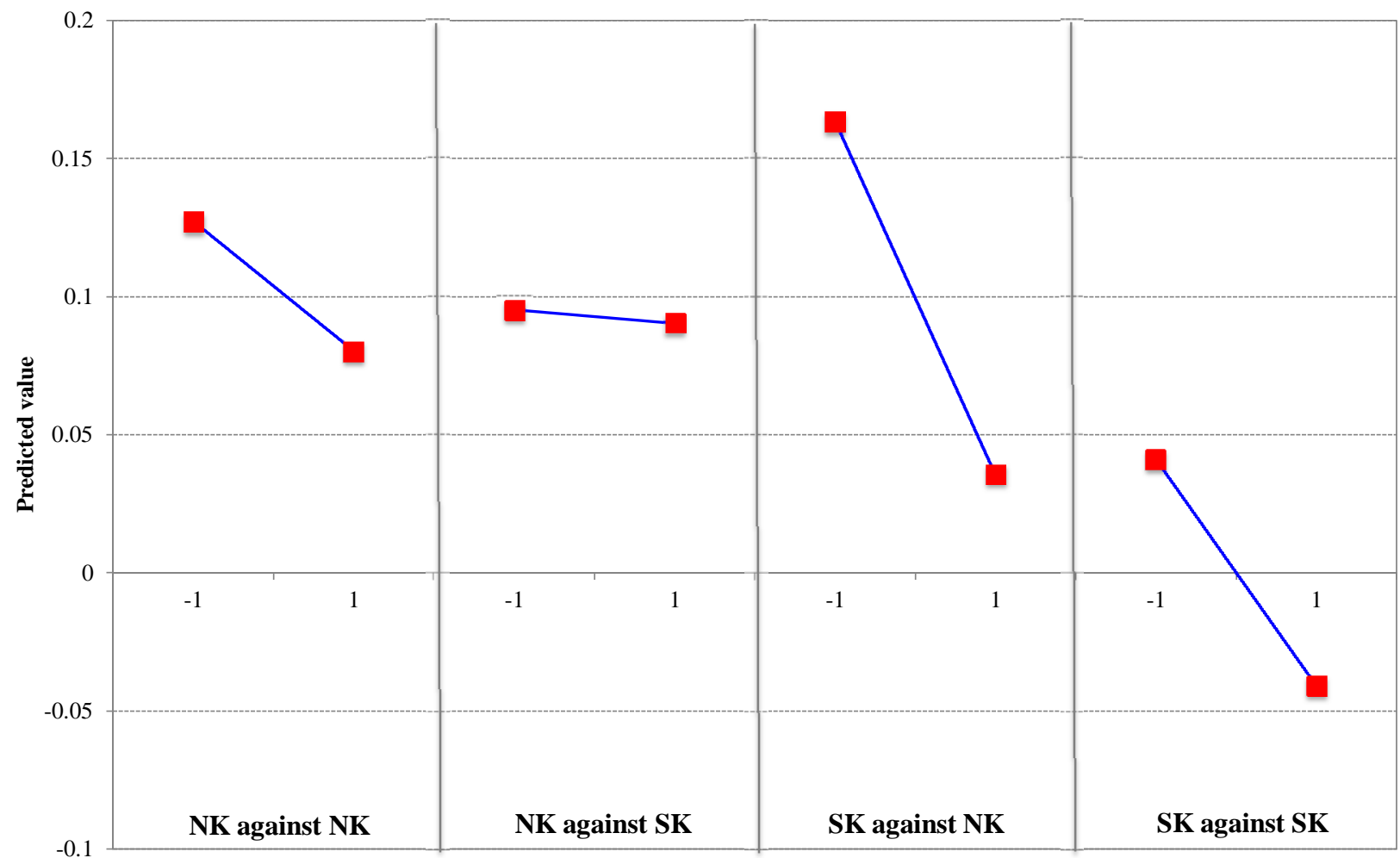

B. Score of attitude toward democracy $=-1$ and 1

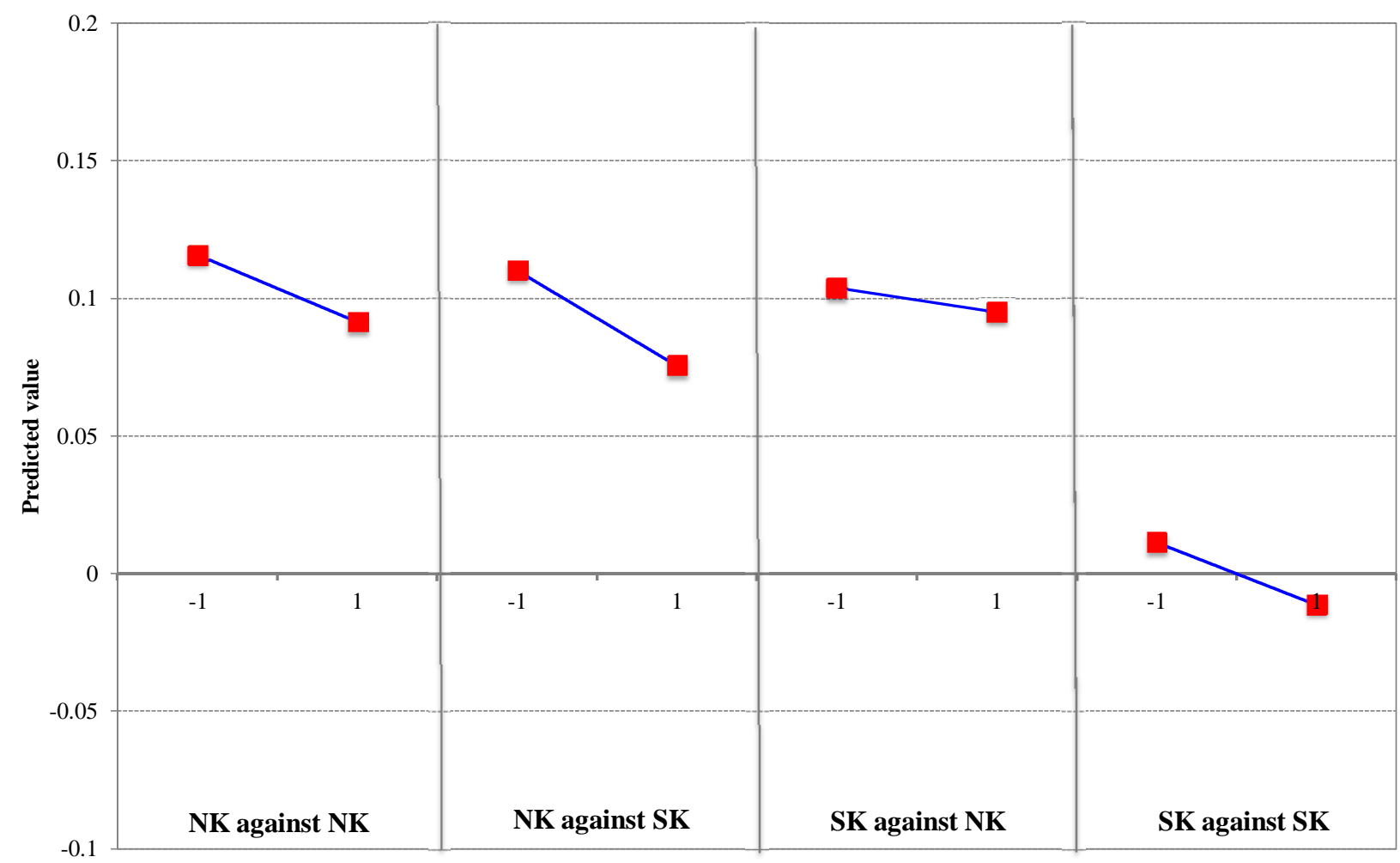

Note. The predicted value of giving is based on the regression of giving behavior on the full set of controls reported in column (6) of Table 7. It is normalized to the value for the case of SK against SK with its corresponding attitudinal score for market economy or democracy being zero. 
Figure 3. Predicted trust behavior conditional on attitudes toward market economy and democracy

A. Score of attitudes toward market economy $=-1$ and 1

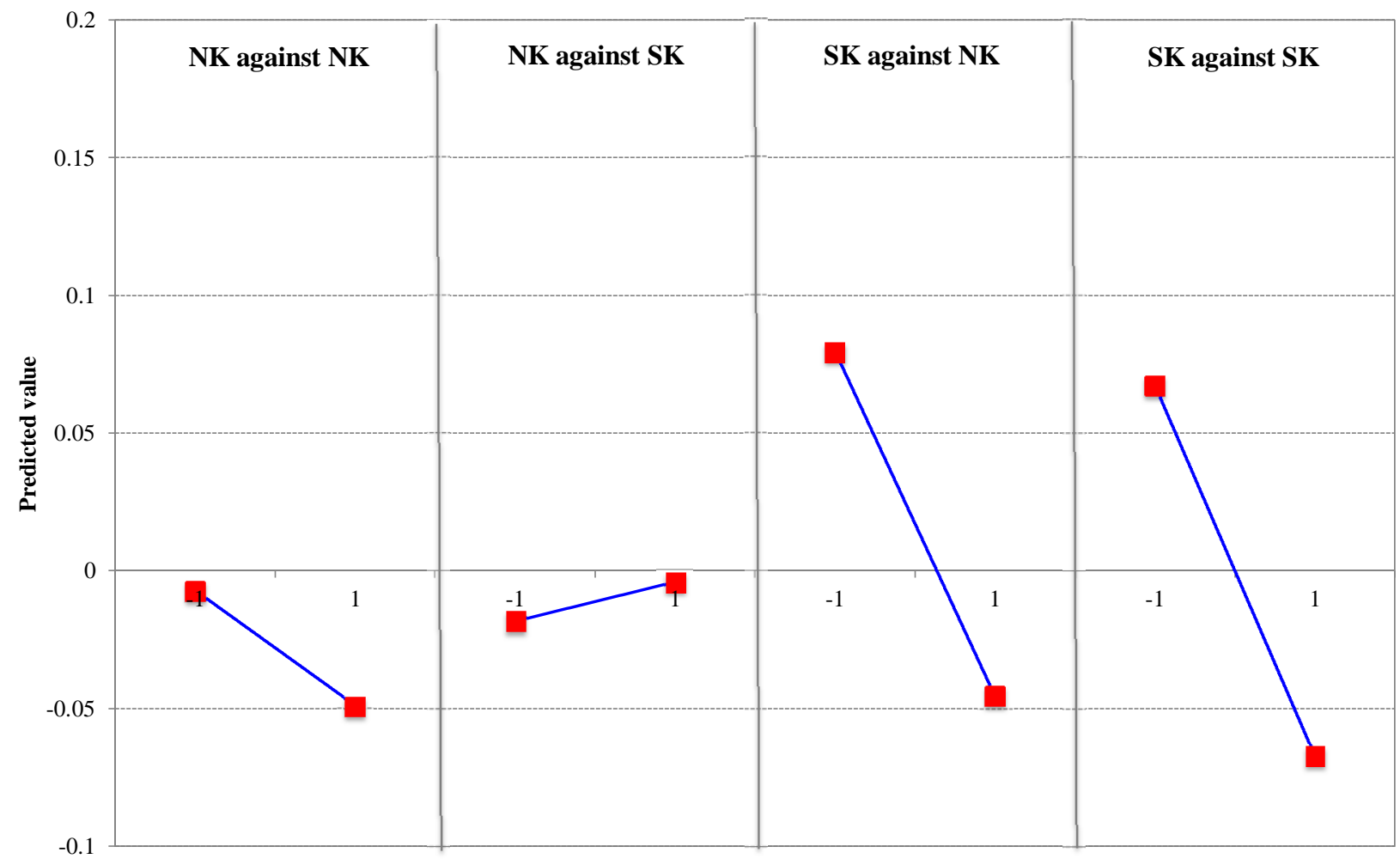

$\underline{\text { B. Score of attitudes toward democracy }=-1 \text { and } 1}$

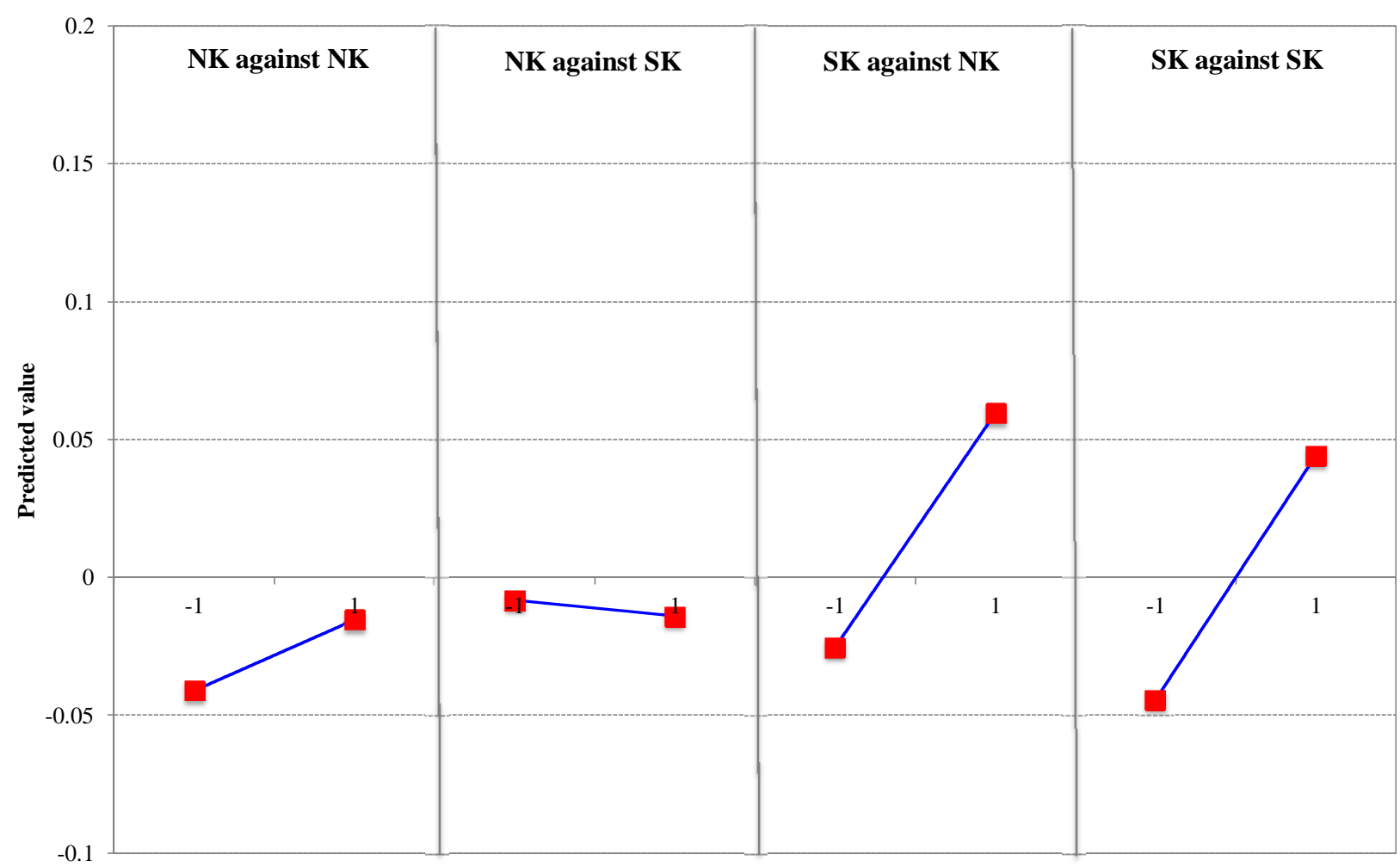

Note. The predicted value of trust behavior is based on the regression of trust behavior on the full set of controls reported in column (6) of Table 8. It is normalized to the value for the case of SK against SK with its corresponding attitudinal score for market economy or democracy being zero. 
$\underline{\text { Table 1. Demographic information and political priming information }}$

\begin{tabular}{|c|c|c|c|c|c|c|}
\hline & \multicolumn{3}{|c|}{ NK subjects } & \multicolumn{3}{|c|}{ SK subjects } \\
\hline & Study 1 & Study 2 & All & Study 1 & Study 2 & All \\
\hline \multicolumn{7}{|c|}{ Demographic information } \\
\hline Male & 0.37 & 0.28 & 0.34 & 0.58 & 0.52 & 0.56 \\
\hline \multicolumn{7}{|l|}{ Age } \\
\hline 22 or younger & 0.16 & 0.25 & 0.19 & 0.67 & 0.59 & 0.65 \\
\hline $23-28$ & 0.21 & 0.56 & 0.33 & 0.33 & 0.41 & 0.35 \\
\hline $29-45$ & 0.37 & 0.19 & 0.31 & 0 & 0 & 0 \\
\hline 46 or older & 0.26 & 0 & 0.17 & 0 & 0 & 0 \\
\hline \multicolumn{7}{|l|}{ Priming } \\
\hline Confrontation & 0.32 & 0.38 & 0.34 & 0.36 & 0.25 & 0.33 \\
\hline Peace-making & 0.34 & 0.43 & 0.37 & 0.35 & 0.39 & 0.36 \\
\hline Control & 0.34 & 0.19 & 0.29 & 0.29 & 0.36 & 0.31 \\
\hline Number of subjects & 133 & 72 & 205 & 166 & 80 & 246 \\
\hline
\end{tabular}


Table 2. Summary of attitudinal responses

\begin{tabular}{|c|c|c|c|}
\hline Variables & $\begin{array}{c}\text { NK subjects } \\
\text { (Std. Dev.) }\end{array}$ & $\begin{array}{l}\text { SK subjects } \\
\text { (Std. Dev.) }\end{array}$ & $\begin{array}{c}(\mathrm{NK}-\mathrm{SK}) \\
(\mathrm{p} \text {-value })\end{array}$ \\
\hline \multicolumn{4}{|l|}{ Attitudes toward institutions } \\
\hline Democracy & $\begin{array}{l}-0.31 \\
(1.02)\end{array}$ & $\begin{array}{c}0.25 \\
(0.91)\end{array}$ & $\begin{array}{c}-0.56 \\
(p<0.01)\end{array}$ \\
\hline Multiple parties & $\begin{array}{l}-0.22 \\
(1.10)\end{array}$ & $\begin{array}{c}0.18 \\
(0.87)\end{array}$ & $\begin{array}{c}-0.4 \\
(\mathrm{p}<0.01)\end{array}$ \\
\hline Voting freedom & $\begin{array}{c}0.04 \\
(1.08)\end{array}$ & $\begin{array}{l}-0.03 \\
(0.93)\end{array}$ & $\begin{array}{c}0.07 \\
(\mathrm{p}=0.48)\end{array}$ \\
\hline Individualism & $\begin{array}{l}-0.33 \\
(1.05)\end{array}$ & $\begin{array}{c}0.28 \\
(0.87)\end{array}$ & $\begin{array}{c}-0.61 \\
(p<0.01)\end{array}$ \\
\hline Market economy & $\begin{array}{l}-0.41 \\
(1.02)\end{array}$ & $\begin{array}{c}0.34 \\
(0.84)\end{array}$ & $\begin{array}{c}-0.75 \\
(p<0.01)\end{array}$ \\
\hline Private ownership & $\begin{array}{l}-0.52 \\
(1.05)\end{array}$ & $\begin{array}{c}0.42 \\
(0.72)\end{array}$ & $\begin{array}{c}-0.94 \\
(p<0.01)\end{array}$ \\
\hline Competition & $\begin{array}{l}-0.18 \\
(1.12)\end{array}$ & $\begin{array}{c}0.15 \\
(0.87)\end{array}$ & $\begin{array}{c}-0.33 \\
(p<0.01)\end{array}$ \\
\hline Performance-based pay & $\begin{array}{l}-0.14 \\
(1.20)\end{array}$ & $\begin{array}{c}0.12 \\
(0.79)\end{array}$ & $\begin{array}{c}-0.26 \\
(p=0.01)\end{array}$ \\
\hline \multicolumn{4}{|l|}{ Identity } \\
\hline Identity as Korean & $\begin{array}{c}0.40 \\
(0.93)\end{array}$ & $\begin{array}{l}-0.33 \\
(0.94)\end{array}$ & $\begin{array}{c}0.73 \\
(p<0.01)\end{array}$ \\
\hline Identity as South Korean & $\begin{array}{c}0.13 \\
(0.99)\end{array}$ & $\begin{array}{l}-0.11 \\
(1.00)\end{array}$ & $\begin{array}{c}0.24 \\
(p=0.01)\end{array}$ \\
\hline Attitudes toward South Korean society & $\begin{array}{c}0.61 \\
(0.85)\end{array}$ & $\begin{array}{l}-0.50 \\
(0.82)\end{array}$ & $\begin{array}{c}1.11 \\
(p<0.01)\end{array}$ \\
\hline Attitudes toward North Korean refugees & $\begin{array}{c}0.19 \\
(1.06)\end{array}$ & $\begin{array}{l}-0.15 \\
(0.92)\end{array}$ & $\begin{array}{c}0.34 \\
(p<0.01)\end{array}$ \\
\hline \multicolumn{4}{|l|}{ Trust / Trustworthiness attitudes (GSS) } \\
\hline Trust & $\begin{array}{l}-0.34 \\
(1.04)\end{array}$ & $\begin{array}{c}0.28 \\
(0.87)\end{array}$ & $\begin{array}{c}-0.62 \\
(p<0.01)\end{array}$ \\
\hline Trustworthiness & $\begin{array}{c}0.15 \\
(1.07)\end{array}$ & $\begin{array}{l}-0.12 \\
(0.92)\end{array}$ & $\begin{array}{c}0.27 \\
(\mathrm{p}<0.01)\end{array}$ \\
\hline Fair & $\begin{array}{c}0.10 \\
(1.03)\end{array}$ & $\begin{array}{l}-0.09 \\
(0.97)\end{array}$ & $\begin{array}{c}0.19 \\
(p=0.04)\end{array}$ \\
\hline Helped & $\begin{array}{c}0.19 \\
(0.99)\end{array}$ & $\begin{array}{l}-0.16 \\
(0.99)\end{array}$ & $\begin{array}{c}0.35 \\
(p<0.01)\end{array}$ \\
\hline \multicolumn{4}{|l|}{ Other attitudinal responses } \\
\hline Risk taking & $\begin{array}{l}-0.50 \\
(1.02)\end{array}$ & $\begin{array}{c}0.41 \\
(0.92)\end{array}$ & $\begin{array}{c}-0.91 \\
(p<0.01)\end{array}$ \\
\hline Discriminated & $\begin{array}{c}0.05 \\
(1.13)\end{array}$ & $\begin{array}{l}-0.04 \\
(0.88)\end{array}$ & $\begin{array}{c}0.09 \\
(p=0.37)\end{array}$ \\
\hline
\end{tabular}

Note. Attitudes toward democracy and market economy, respectively, are constructed by summing each respondent's responses to multiple questions, re-ordering them when necessary so that higher scores reflect greater support for democracy and market economy. For each attitudinal variable, we normalize the score to generate a measure with sample mean 0 and standard deviation 1. 
Table 3. Fraction of subject by percentage of money allocated to the first other in the other-other dictator game

\begin{tabular}{|c|c|c|c|c|c|c|}
\hline & \multirow[b]{2}{*}{ Matching } & \multirow[b]{2}{*}{ Subject } & \multicolumn{3}{|c|}{ Percentage of money allocation } & \multirow[b]{2}{*}{$\begin{array}{c}\text { Wilcoxon rank- } \\
\text { sum test }\end{array}$} \\
\hline & & & $<50 \%$ & $=50 \%$ & $>50 \%$ & \\
\hline \multirow{6}{*}{ Study 1} & \multirow{2}{*}{ NK vs. NK } & NK & 0.01 & 0.89 & 0.11 & \\
\hline & & SK & 0.04 & 0.86 & 0.10 & 0.219 \\
\hline & \multirow{2}{*}{ SK vs. SK } & NK & 0.03 & 0.83 & 0.14 & \\
\hline & & SK & 0.10 & 0.77 & 0.13 & 0.087 \\
\hline & \multirow{2}{*}{ NK vs. SK } & $\mathrm{NK}$ & 0.07 & 0.53 & 0.40 & \\
\hline & & SK & 0.22 & 0.29 & 0.49 & 0.910 \\
\hline \multirow{6}{*}{ Study 2} & \multirow{2}{*}{ NK vs. NK } & NK & 0.04 & 0.79 & 0.17 & \\
\hline & & SK & 0.05 & 0.84 & 0.11 & 0.400 \\
\hline & \multirow{2}{*}{ SK vs. SK } & NK & 0.10 & 0.74 & 0.17 & \\
\hline & & SK & 0.08 & 0.78 & 0.15 & 0.921 \\
\hline & \multirow{2}{*}{ NK vs. SK } & NK & 0.06 & 0.67 & 0.28 & \\
\hline & & SK & 0.23 & 0.45 & 0.33 & 0.186 \\
\hline
\end{tabular}

Note. We use the Wilcoxon rank-sum test to compare the distributions of money allocation by the NK and the SK group in each matching case and report $p$-values in the last column. 
Table 4. Mean fraction of money given to other in the self-other dictator game

\begin{tabular}{|c|c|c|c|c|c|c|c|c|c|c|}
\hline \multirow[b]{4}{*}{ Budget } & \multicolumn{6}{|c|}{ A. Study 1} & & & & \\
\hline & \multirow[b]{3}{*}{$\begin{array}{l}\text { Income } \\
\text { (KRW) }\end{array}$} & \multirow[b]{3}{*}{$\begin{array}{c}\text { Relative price } \\
\text { of giving }\end{array}$} & \multicolumn{2}{|c|}{ NK subjects } & \multicolumn{2}{|c|}{ SK subjects } & \multirow{2}{*}{\multicolumn{4}{|c|}{$t$-stat }} \\
\hline & & & (1) & (2) & (3) & (4) & & & & \\
\hline & & & against NK & against SK & against NK & against SK & (1) - (2) & (3) - (4) & (1) - (3) & (2) - (4) \\
\hline 1 & 10,000 & $1 / 3$ & 0.560 & 0.527 & 0.469 & 0.337 & 1.871 & 7.475 & 2.638 & 5.744 \\
\hline 2 & 15,000 & 1 & 0.452 & 0.434 & 0.325 & 0.208 & 1.074 & 7.430 & 4.374 & 8.521 \\
\hline 3 & 15,000 & $1 / 2$ & 0.521 & 0.501 & 0.416 & 0.298 & 1.228 & 7.295 & 3.281 & 6.672 \\
\hline 4 & 18,000 & $1 / 2$ & 0.536 & 0.504 & 0.413 & 0.297 & 1.908 & 7.330 & 3.826 & 6.620 \\
\hline 5 & 25,000 & 1 & 0.449 & 0.437 & 0.307 & 0.207 & 0.728 & 6.573 & 4.885 & 8.846 \\
\hline 6 & 30,000 & 2 & 0.382 & 0.392 & 0.190 & 0.118 & -0.653 & 5.981 & 6.687 & 10.886 \\
\hline 7 & 30,000 & 3 & 0.367 & 0.366 & 0.167 & 0.102 & 0.014 & 5.556 & 7.037 & 10.336 \\
\hline 8 & 36,000 & 2 & 0.386 & 0.399 & 0.184 & 0.123 & -0.680 & 5.340 & 7.093 & 10.652 \\
\hline
\end{tabular}

B. Study 2

\begin{tabular}{|c|c|c|c|c|c|c|c|c|c|c|}
\hline \multirow[b]{3}{*}{ Budget } & \multirow[b]{3}{*}{$\begin{array}{l}\text { Income } \\
\text { (KRW) }\end{array}$} & \multirow[b]{3}{*}{$\begin{array}{l}\text { Relative price } \\
\text { of giving }\end{array}$} & \multicolumn{2}{|c|}{ NK subjects } & \multicolumn{2}{|c|}{ SK subjects } & \multirow{2}{*}{\multicolumn{4}{|c|}{$t$-stat }} \\
\hline & & & (1) & (2) & (3) & (4) & & & & \\
\hline & & & against NK & against SK & against NK & against SK & (1) - (2) & (3) - (4) & (1) - (3) & (2) - (4) \\
\hline 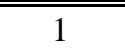 & 10,000 & $1 / 3$ & 0.584 & 0.579 & 0.381 & 0.324 & 0.268 & 2.384 & 4.029 & 5.364 \\
\hline 2 & 15,000 & 1 & 0.394 & 0.353 & 0.266 & 0.206 & 2.099 & 3.563 & 3.219 & 4.127 \\
\hline 3 & 15,000 & $1 / 2$ & 0.525 & 0.521 & 0.347 & 0.302 & 0.163 & 2.286 & 3.734 & 4.756 \\
\hline 4 & 18,000 & $1 / 2$ & 0.551 & 0.513 & 0.344 & 0.282 & 2.149 & 3.037 & 4.481 & 5.075 \\
\hline 5 & 25,000 & 1 & 0.365 & 0.368 & 0.266 & 0.190 & -0.173 & 4.281 & 2.649 & 5.028 \\
\hline 6 & 30,000 & 2 & 0.280 & 0.297 & 0.196 & 0.140 & -0.854 & 4.379 & 2.183 & 4.187 \\
\hline 7 & 30,000 & 3 & 0.248 & 0.252 & 0.166 & 0.124 & -0.289 & 3.512 & 2.202 & 3.632 \\
\hline 8 & 36,000 & 2 & 0.275 & 0.271 & 0.191 & 0.141 & 0.278 & 3.929 & 2.263 & 3.764 \\
\hline
\end{tabular}

Note. The last four columns in each table report values of $t$-statistics on the equality of means for two compared groups. 
Table 5. Individual-level classification: types of preferences for giving

A. Study 1 and Study 2

\begin{tabular}{|c|c|c|c|c|c|c|c|c|c|c|c|c|}
\hline \multirow[b]{3}{*}{$\begin{array}{c}\text { Preference } \\
\text { type }\end{array}$} & \multicolumn{6}{|c|}{ NK subjects } & \multicolumn{6}{|c|}{ SK subjects } \\
\hline & \multicolumn{3}{|c|}{ against NK } & \multicolumn{3}{|c|}{ against SK } & \multicolumn{3}{|c|}{ against NK } & \multicolumn{3}{|c|}{ against SK } \\
\hline & Strong & Weak & Total & Strong & Weak & Total & Strong & Weak & Total & Strong & Weak & Total \\
\hline Selfish & 0.04 & 0.15 & 0.19 & 0.05 & 0.15 & 0.20 & 0.22 & 0.22 & 0.43 & 0.30 & 0.27 & 0.57 \\
\hline Altruistic & 0.01 & 0.02 & 0.04 & 0.03 & 0.03 & 0.06 & 0.01 & 0.01 & 0.02 & 0.00 & 0.00 & 0.00 \\
\hline Leontief & 0.17 & 0.47 & 0.64 & 0.16 & 0.48 & 0.63 & 0.09 & 0.32 & 0.41 & 0.09 & 0.24 & 0.32 \\
\hline $\begin{array}{c}\text { Perfect } \\
\text { substitute }\end{array}$ & 0.07 & 0.06 & 0.13 & 0.06 & 0.04 & 0.11 & 0.05 & 0.09 & 0.13 & 0.04 & 0.06 & 0.10 \\
\hline \# of obs. & 61 & 144 & 205 & 62 & 143 & 205 & 91 & 155 & 246 & 106 & 140 & 246 \\
\hline
\end{tabular}

B. Study 1

\begin{tabular}{|c|c|c|c|c|c|c|c|c|c|c|c|c|}
\hline \multirow[b]{3}{*}{$\begin{array}{c}\text { Preference } \\
\text { type }\end{array}$} & \multicolumn{6}{|c|}{ NK subjects } & \multicolumn{6}{|c|}{ SK subjects } \\
\hline & \multicolumn{3}{|c|}{ against NK } & \multicolumn{3}{|c|}{ against SK } & \multicolumn{3}{|c|}{ against NK } & \multicolumn{3}{|c|}{ against SK } \\
\hline & Strong & Weak & Total & Strong & Weak & Total & Strong & Weak & Total & Strong & Weak & Total \\
\hline "Selfish & 0.02 & 0.15 & 0.17 & 0.04 & 0.16 & 0.20 & 0.20 & 0.23 & 0.43 & 0.31 & 0.27 & 0.58 \\
\hline Altruistic & 0.02 & 0.03 & 0.05 & 0.05 & 0.03 & 0.08 & 0.02 & 0.01 & 0.02 & 0.01 & 0.00 & 0.01 \\
\hline Leontief & 0.17 & 0.52 & 0.70 & 0.16 & 0.52 & 0.68 & 0.07 & 0.31 & 0.39 & 0.07 & 0.23 & 0.30 \\
\hline $\begin{array}{c}\text { Perfect } \\
\text { substitute }\end{array}$ & 0.05 & 0.03 & 0.08 & 0.03 & 0.02 & 0.05 & 0.05 & 0.11 & 0.16 & 0.04 & 0.08 & 0.12 \\
\hline \# of obs. & 36 & 97 & 133 & 37 & 96 & 133 & 57 & 109 & 166 & 71 & 95 & 166 \\
\hline
\end{tabular}

\section{Study 2}

\begin{tabular}{|c|c|c|c|c|c|c|c|c|c|c|c|c|}
\hline \multirow[b]{3}{*}{$\begin{array}{c}\text { Preference } \\
\text { type }\end{array}$} & \multicolumn{6}{|c|}{ NK subjects } & \multicolumn{6}{|c|}{ SK subjects } \\
\hline & \multicolumn{3}{|c|}{ against NK } & \multicolumn{3}{|c|}{ against SK } & \multicolumn{3}{|c|}{ against $\mathrm{NK}$} & \multicolumn{3}{|c|}{ against SK } \\
\hline & Strong & Weak & Total & Strong & Weak & Total & Strong & Weak & Total & Strong & Weak & Total \\
\hline Selfish & 0.07 & 0.14 & 0.21 & 0.07 & 0.13 & 0.19 & 0.26 & 0.19 & 0.45 & 0.28 & 0.29 & 0.56 \\
\hline Altruistic & 0.00 & 0.01 & 0.01 & 0.00 & 0.03 & 0.03 & 0.00 & 0.01 & 0.01 & 0.00 & 0.00 & 0.00 \\
\hline Leontief & 0.17 & 0.38 & 0.54 & 0.15 & 0.40 & 0.56 & 0.13 & 0.34 & 0.46 & 0.13 & 0.25 & 0.38 \\
\hline $\begin{array}{c}\text { Perfect } \\
\text { substitute }\end{array}$ & 0.11 & 0.13 & 0.24 & 0.13 & 0.10 & 0.22 & 0.04 & 0.04 & 0.08 & 0.04 & 0.03 & 0.06 \\
\hline \# of obs. & 25 & 47 & 72 & 25 & 47 & 72 & 34 & 46 & 80 & 35 & 45 & 80 \\
\hline
\end{tabular}

Notes. In classifying weak types, we minimize the Euclidean distance between the observed behavior and the behavior predicted by each preference type. An NK subject whose behavior against an NK opponent is minimized by types of Leontief and perfect substitute. The type assignement of that subject is equally distributed between these two types. 
Table 6. Behaviors of the first and second movers in the trust game

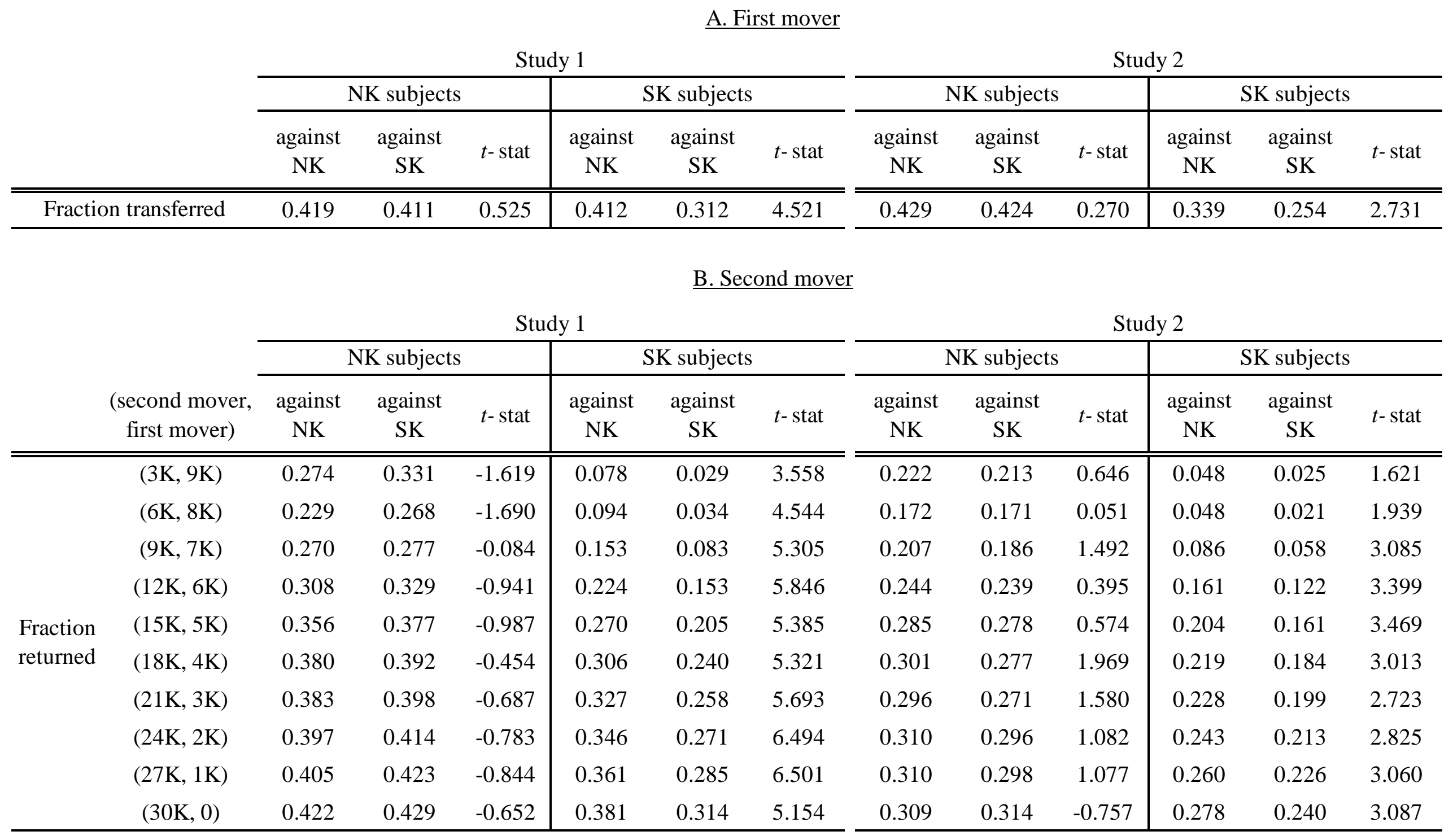

Note. We report values of $t$-statistics on the equality of average fractions of money against NK and SK opponents for each group. 
Table 7. Regression analysis of giving behavior in the self-other dictator game

\begin{tabular}{|c|c|c|c|c|c|c|}
\hline $\begin{array}{l}\text { Dependent variable: Fraction of } \\
\text { money given to other }\end{array}$ & (1) & (2) & (3) & (4) & $(5)$ & $(6)$ \\
\hline \multicolumn{7}{|l|}{ Matching } \\
\hline$N K$ & $\begin{array}{c}0.194 * * * \\
(0.033)\end{array}$ & $\begin{array}{l}0.155^{* * *} \\
(0.033)\end{array}$ & $\begin{array}{c}0.088 * * \\
(0.044)\end{array}$ & $\begin{array}{l}0.162 * * * \\
(0.033)\end{array}$ & $\begin{array}{c}0.098 * * \\
(0.044)\end{array}$ & $\begin{array}{c}0.093^{* *} \\
(0.044)\end{array}$ \\
\hline$N K r$ & $\begin{array}{c}0.083 * * * \\
(0.009)\end{array}$ & $\begin{array}{c}0.083 * * * \\
(0.009)\end{array}$ & $\begin{array}{c}0.089 * * * \\
(0.009)\end{array}$ & $\begin{array}{c}0.089 * * * \\
(0.010)\end{array}$ & $\begin{array}{c}0.094 * * * \\
(0.011)\end{array}$ & $\begin{array}{c}0.099 * * * \\
(0.014)\end{array}$ \\
\hline$N K \times N K r$ & $\begin{array}{c}-0.073 * * * \\
(0.013)\end{array}$ & $\begin{array}{c}-0.069 * * * \\
(0.013)\end{array}$ & $\begin{array}{c}-0.075 * * * \\
(0.015)\end{array}$ & $\begin{array}{c}-0.078^{* * *} * \\
(0.015)\end{array}$ & $\begin{array}{c}-0.088 * * * \\
(0.017)\end{array}$ & $\begin{array}{c}-0.089 * * * \\
(0.018)\end{array}$ \\
\hline \multicolumn{7}{|l|}{ Priming on historical events } \\
\hline Confrontation & $\begin{array}{l}-0.004 \\
(0.023)\end{array}$ & $\begin{array}{l}-0.006 \\
(0.023)\end{array}$ & $\begin{array}{c}0.004 \\
(0.024)\end{array}$ & $\begin{array}{l}-0.006 \\
(0.024)\end{array}$ & $\begin{array}{c}0.004 \\
(0.025)\end{array}$ & $\begin{array}{c}0.003 \\
(0.025)\end{array}$ \\
\hline Peace-making & $\begin{array}{l}0.008 \\
(0.024)\end{array}$ & $\begin{array}{c}0.009 \\
(0.024)\end{array}$ & $\begin{array}{c}0.012 \\
(0.025)\end{array}$ & $\begin{array}{c}0.008 \\
(0.024)\end{array}$ & $\begin{array}{c}0.011 \\
(0.025)\end{array}$ & $\begin{array}{c}0.013 \\
(0.025)\end{array}$ \\
\hline \multicolumn{7}{|l|}{ Attitudes toward institutions } \\
\hline Market economy & & $\begin{array}{c}-0.030 * * * \\
(0.009)\end{array}$ & $\begin{array}{c}-0.032 * * * \\
(0.011)\end{array}$ & $\begin{array}{c}-0.039 * * * \\
(0.015)\end{array}$ & $\begin{array}{c}-0.043 * * * \\
(0.016)\end{array}$ & $\begin{array}{c}-0.041^{* *} \\
(0.016)\end{array}$ \\
\hline$\times N K$ & & & & $\begin{array}{c}0.035^{*} \\
(0.020)\end{array}$ & $\begin{array}{c}0.041 * * \\
(0.021)\end{array}$ & $\begin{array}{l}0.039 * \\
(0.022)\end{array}$ \\
\hline$\times N K r$ & & & & $\begin{array}{c}-0.023 * * \\
(0.011)\end{array}$ & $\begin{array}{l}-0.021 * \\
(0.012)\end{array}$ & $\begin{array}{l}-0.023^{*} \\
(0.013)\end{array}$ \\
\hline$\times N K \times N K r$ & & & & $\begin{array}{c}0.008 \\
(0.016)\end{array}$ & $\begin{array}{l}-0.000 \\
(0.017)\end{array}$ & $\begin{array}{c}0.002 \\
(0.018)\end{array}$ \\
\hline Democracy & & $\begin{array}{l}-0.007 \\
(0.009)\end{array}$ & $\begin{array}{l}-0.009 \\
(0.010)\end{array}$ & $\begin{array}{l}-0.009 \\
(0.013)\end{array}$ & $\begin{array}{l}-0.011 \\
(0.013)\end{array}$ & $\begin{array}{l}-0.011 \\
(0.013)\end{array}$ \\
\hline$\times N K$ & & & & $\begin{array}{l}-0.005 \\
(0.020)\end{array}$ & $\begin{array}{l}-0.004 \\
(0.021)\end{array}$ & $\begin{array}{l}-0.006 \\
(0.021)\end{array}$ \\
\hline$\times N K r$ & & & & $\begin{array}{c}0.007 \\
(0.010)\end{array}$ & $\begin{array}{c}0.006 \\
(0.010)\end{array}$ & $\begin{array}{c}0.007 \\
(0.010)\end{array}$ \\
\hline$\times N K \times N K r$ & & & & $\begin{array}{c}0.000 \\
(0.013)\end{array}$ & $\begin{array}{c}0.001 \\
(0.014)\end{array}$ & $\begin{array}{l}-0.002 \\
(0.015)\end{array}$ \\
\hline Constant & $\begin{array}{c}0.314^{* * * *} \\
(0.066)\end{array}$ & $\begin{array}{c}0.328^{* * * *} \\
(0.067)\end{array}$ & $\begin{array}{c}0.373^{* * * *} \\
(0.074)\end{array}$ & $\begin{array}{c}0.329 * * * \\
(0.067) \\
\end{array}$ & $\begin{array}{c}0.374 * * * \\
(0.074) \\
\end{array}$ & $\begin{array}{c}0.388 * * * \\
(0.076) \\
\end{array}$ \\
\hline Demographic controls & Yes & Yes & Yes & Yes & Yes & Yes \\
\hline Other experimental controls & Yes & Yes & Yes & Yes & Yes & Yes \\
\hline Other attitudinal controls & No & No & Yes & No & Yes & Yes \\
\hline Interactions with other attitudinal contro] & No & No & No & No & No & Yes \\
\hline Observations & 7,184 & 7,056 & 6,560 & 7,056 & 6,560 & 6,560 \\
\hline R-squared & 0.221 & 0.236 & 0.258 & 0.241 & 0.264 & 0.275 \\
\hline
\end{tabular}

Notes. Robust standard errors, clustered by individual subject, are reported in parentheses. *, **, and *** represent $10 \%, 5 \%$, and $1 \%$ significance level. $N K$ is an indicator of NK subject being a decision-maker, while $N K r$ is an indicator of NK subject being a recipient. Demographic controls include gender, four categories of age, and their interactions with the NK dummy. Other experimental controls contain the natural logarithms of amount of endowment and relative price of giving, a dummy for Study 1, and the size of session. Other attitudinal controls include national identity, attitudes toward NK refugees, trust/trustworthiness attitudes (GSS), and survey responses on risk taking and experience of being discriminated against. They are also interacted with $N K, N K r$, and $N K \times N K r$ dummies. 
Table 8. Regression analysis of trust behavior: the first mover in the trust game

\begin{tabular}{|c|c|c|c|c|c|c|}
\hline $\begin{array}{l}\text { Dependent variable: Fraction of } \\
\text { money invested by the first mover }\end{array}$ & (1) & (2) & (3) & (4) & $(5)$ & (6) \\
\hline \multicolumn{7}{|l|}{ Matching } \\
\hline$N K$ & $\begin{array}{c}0.001 \\
(0.041)\end{array}$ & $\begin{array}{l}-0.025 \\
(0.042)\end{array}$ & $\begin{array}{l}-0.022 \\
(0.056)\end{array}$ & $\begin{array}{l}-0.021 \\
(0.042)\end{array}$ & $\begin{array}{l}-0.020 \\
(0.057)\end{array}$ & $\begin{array}{l}-0.011 \\
(0.059)\end{array}$ \\
\hline$N K r$ & $\begin{array}{l}0.034^{*} \\
(0.018)\end{array}$ & $\begin{array}{l}0.034 * \\
(0.018)\end{array}$ & $\begin{array}{l}0.035^{*} \\
(0.018)\end{array}$ & $\begin{array}{l}0.035^{*} \\
(0.019)\end{array}$ & $\begin{array}{l}0.035^{*} \\
(0.019)\end{array}$ & $\begin{array}{c}0.017 \\
(0.021)\end{array}$ \\
\hline$N K \times N K r$ & $\begin{array}{l}-0.043^{*} \\
(0.022)\end{array}$ & $\begin{array}{l}-0.039^{*} \\
(0.022)\end{array}$ & $\begin{array}{l}-0.035 \\
(0.023)\end{array}$ & $\begin{array}{l}-0.043^{*} \\
(0.023)\end{array}$ & $\begin{array}{l}-0.036 \\
(0.025)\end{array}$ & $\begin{array}{l}-0.034 \\
(0.031)\end{array}$ \\
\hline \multicolumn{7}{|l|}{ Control for altruism } \\
\hline Fraction of money given in the DG & $\begin{array}{c}0.689 * * * \\
(0.043)\end{array}$ & $\begin{array}{c}0.688^{* * *} \\
(0.043)\end{array}$ & $\begin{array}{c}0.676^{* * * *} \\
(0.047)\end{array}$ & $\begin{array}{c}0.681^{* * * *} \\
(0.043)\end{array}$ & $\begin{array}{c}0.671 * * * \\
(0.047)\end{array}$ & $\begin{array}{c}0.665^{* * * *} \\
(0.047)\end{array}$ \\
\hline \multicolumn{7}{|l|}{ Priming on historical events } \\
\hline Confrontation & $\begin{array}{l}-0.020 \\
(0.027)\end{array}$ & $\begin{array}{l}-0.027 \\
(0.028)\end{array}$ & $\begin{array}{l}-0.034 \\
(0.030)\end{array}$ & $\begin{array}{l}-0.032 \\
(0.028)\end{array}$ & $\begin{array}{l}-0.039 \\
(0.031)\end{array}$ & $\begin{array}{l}-0.044 \\
(0.032)\end{array}$ \\
\hline Peace-making & $\begin{array}{l}-0.020 \\
(0.028)\end{array}$ & $\begin{array}{l}-0.028 \\
(0.028)\end{array}$ & $\begin{array}{l}-0.021 \\
(0.029)\end{array}$ & $\begin{array}{l}-0.033 \\
(0.028)\end{array}$ & $\begin{array}{l}-0.026 \\
(0.029)\end{array}$ & $\begin{array}{l}-0.026 \\
(0.031)\end{array}$ \\
\hline \multicolumn{7}{|l|}{ Attitudes toward institutions } \\
\hline Market economy & & $\begin{array}{c}-0.035^{* * *} \\
(0.012)\end{array}$ & $\begin{array}{c}-0.035^{* * *} \\
(0.012)\end{array}$ & $\begin{array}{c}-0.063 * * * \\
(0.022)\end{array}$ & $\begin{array}{c}-0.066 \text { *** } \\
(0.022)\end{array}$ & $\begin{array}{c}-0.067 * * * \\
(0.024)\end{array}$ \\
\hline$\times N K$ & & & & $\begin{array}{c}0.068 * * \\
(0.027)\end{array}$ & $\begin{array}{c}0.070 * * \\
(0.027)\end{array}$ & $\begin{array}{c}0.074 * * \\
(0.029)\end{array}$ \\
\hline$\times N K r$ & & & & $\begin{array}{l}-0.007 \\
(0.019)\end{array}$ & $\begin{array}{l}-0.002 \\
(0.019)\end{array}$ & $\begin{array}{c}0.005 \\
(0.022)\end{array}$ \\
\hline$\times N K \times N K r$ & & & & $\begin{array}{l}-0.014 \\
(0.026)\end{array}$ & $\begin{array}{l}-0.017 \\
(0.027)\end{array}$ & $\begin{array}{l}-0.033 \\
(0.030)\end{array}$ \\
\hline Democracy & & $\begin{array}{c}0.029 * * \\
(0.012)\end{array}$ & $\begin{array}{c}0.030^{* *} \\
(0.013)\end{array}$ & $\begin{array}{c}0.045^{* *} \\
(0.020)\end{array}$ & $\begin{array}{c}0.047 * * \\
(0.021)\end{array}$ & $\begin{array}{c}0.044 * * \\
(0.021)\end{array}$ \\
\hline$\times N K$ & & & & $\begin{array}{l}-0.050^{*} \\
(0.026)\end{array}$ & $\begin{array}{c}-0.053^{*} \\
(0.027)\end{array}$ & $\begin{array}{l}-0.047 \\
(0.029)\end{array}$ \\
\hline$\times N K r$ & & & & $\begin{array}{c}0.007 \\
(0.018)\end{array}$ & $\begin{array}{c}0.004 \\
(0.019)\end{array}$ & $\begin{array}{l}-0.002 \\
(0.020)\end{array}$ \\
\hline$\times N K \times N K r$ & & & & $\begin{array}{c}0.012 \\
(0.023)\end{array}$ & $\begin{array}{c}0.018 \\
(0.025)\end{array}$ & $\begin{array}{c}0.018 \\
(0.025)\end{array}$ \\
\hline Constant & $\begin{array}{c}0.117 * * * \\
(0.043)\end{array}$ & $\begin{array}{c}0.120^{* * * *} \\
(0.045)\end{array}$ & $\begin{array}{c}0.117 * * \\
(0.057) \\
\end{array}$ & $\begin{array}{c}0.131 * * * \\
(0.046) \\
\end{array}$ & $\begin{array}{c}0.130 * * \\
(0.058) \\
\end{array}$ & $\begin{array}{c}0.154 * * \\
(0.061) \\
\end{array}$ \\
\hline Demographic controls & Yes & Yes & Yes & Yes & Yes & Yes \\
\hline Other experimental controls & Yes & Yes & Yes & Yes & Yes & Yes \\
\hline Other attitudinal controls & No & No & Yes & No & Yes & Yes \\
\hline Interactions with other attitudinal cont 1 & No & No & No & No & No & Yes \\
\hline Observations & 896 & 880 & 818 & 880 & 818 & 818 \\
\hline R-squared & 0.400 & 0.414 & 0.414 & 0.423 & 0.423 & 0.437 \\
\hline
\end{tabular}

Notes. Robust standard errors, clusterd by individual subject, are reported in parentheses. *, **, and *** represent $10 \%, 5 \%$, and $1 \%$ significance level. $N K$ is an indicator of NK subject being a decision-maker, while $N K r$ is an indicator of NK subject being a receipient. Demographic controls include gender, four categories of age, and their interactions with the NK dummy. Other experimental controls contain a dummy for Study 1 and the size of session. Other attitudinal controls include national identity, attitudes toward NK refugees, trust/trustworthiness attitudes (GSS), and survey responses on risk taking and experience of being discriminated against. They are also interacted with $N K, N K r$, and $N K \times N K r$ dummies. 
Table 9. Regression analysis of reciprocity behavior: the second mover in the trust game

\begin{tabular}{|c|c|c|c|c|c|c|}
\hline $\begin{array}{l}\text { Dependent variable: Fraction of } \\
\text { money returned by the second mover }\end{array}$ & (1) & $(2)$ & (3) & (4) & $(5)$ & $(6)$ \\
\hline \multicolumn{7}{|l|}{ Matching } \\
\hline$N K$ & $\begin{array}{c}0.011 \\
(0.030)\end{array}$ & $\begin{array}{l}-0.006 \\
(0.030)\end{array}$ & $\begin{array}{l}-0.004 \\
(0.038)\end{array}$ & $\begin{array}{l}-0.004 \\
(0.030)\end{array}$ & $\begin{array}{l}-0.002 \\
(0.038)\end{array}$ & $\begin{array}{l}-0.003 \\
(0.040)\end{array}$ \\
\hline$N K r$ & $\begin{array}{c}0.009 \\
(0.008)\end{array}$ & $\begin{array}{c}0.009 \\
(0.008)\end{array}$ & $\begin{array}{c}0.010 \\
(0.008)\end{array}$ & $\begin{array}{c}0.008 \\
(0.009)\end{array}$ & $\begin{array}{c}0.009 \\
(0.009)\end{array}$ & $\begin{array}{c}0.000 \\
(0.011)\end{array}$ \\
\hline$N K \times N K r$ & $\begin{array}{l}-0.019 \\
(0.014)\end{array}$ & $\begin{array}{l}-0.016 \\
(0.013)\end{array}$ & $\begin{array}{l}-0.015 \\
(0.015)\end{array}$ & $\begin{array}{l}-0.019 \\
(0.015)\end{array}$ & $\begin{array}{l}-0.018 \\
(0.016)\end{array}$ & $\begin{array}{l}-0.008 \\
(0.017)\end{array}$ \\
\hline \multicolumn{7}{|l|}{ Control for giving preferences } \\
\hline Fraction of money given in the DG & $\begin{array}{l}0.511 * * * \\
(0.036)\end{array}$ & $\begin{array}{c}0.507 * * * \\
(0.036)\end{array}$ & $\begin{array}{l}0.512 * * * \\
(0.037)\end{array}$ & $\begin{array}{c}0.506 * * * \\
(0.037)\end{array}$ & $\begin{array}{l}0.510 * * * \\
(0.038)\end{array}$ & $\begin{array}{c}0.504 * * * \\
(0.037)\end{array}$ \\
\hline $\mathbf{1}\{27 \mathrm{~K}\}$ & $\begin{array}{c}0.029 * * * \\
(0.004)\end{array}$ & $\begin{array}{c}0.030 * * * \\
(0.004)\end{array}$ & $\begin{array}{c}0.030 * * * \\
(0.004)\end{array}$ & $\begin{array}{c}0.030 * * * \\
(0.004)\end{array}$ & $\begin{array}{c}0.030 * * * \\
(0.004)\end{array}$ & $\begin{array}{c}0.030 * * * \\
(0.004)\end{array}$ \\
\hline \multicolumn{7}{|l|}{ Priming on historical events } \\
\hline Confrontation & $\begin{array}{l}-0.018 \\
(0.019)\end{array}$ & $\begin{array}{l}-0.021 \\
(0.019)\end{array}$ & $\begin{array}{c}-0.017 \\
(0.020)\end{array}$ & $\begin{array}{l}-0.023 \\
(0.019)\end{array}$ & $\begin{array}{c}-0.018 \\
(0.020)\end{array}$ & $\begin{array}{l}-0.018 \\
(0.020)\end{array}$ \\
\hline Peace-making & $\begin{array}{c}-0.033 * \\
(0.018)\end{array}$ & $\begin{array}{c}-0.036 * * \\
(0.018)\end{array}$ & $\begin{array}{l}-0.029 \\
(0.018)\end{array}$ & $\begin{array}{c}-0.038 * * \\
(0.018)\end{array}$ & $\begin{array}{c}-0.031 \\
(0.019)\end{array}$ & $\begin{array}{l}-0.026 \\
(0.019)\end{array}$ \\
\hline \multicolumn{7}{|l|}{ Attitudes toward institutions } \\
\hline Market economy & & $\begin{array}{l}-0.003 \\
(0.009)\end{array}$ & $\begin{array}{c}0.004 \\
(0.010)\end{array}$ & $\begin{array}{c}-0.004 \\
(0.012)\end{array}$ & $\begin{array}{c}0.002 \\
(0.012)\end{array}$ & $\begin{array}{c}-0.001 \\
(0.013)\end{array}$ \\
\hline$\times N K$ & & & & $\begin{array}{c}0.009 \\
(0.020)\end{array}$ & $\begin{array}{c}0.009 \\
(0.020)\end{array}$ & $\begin{array}{c}0.011 \\
(0.021)\end{array}$ \\
\hline$\times N K r$ & & & & $\begin{array}{c}-0.011 \\
(0.011)\end{array}$ & $\begin{array}{l}-0.010 \\
(0.011)\end{array}$ & $\begin{array}{l}-0.005 \\
(0.013)\end{array}$ \\
\hline$\times N K \times N K r$ & & & & $\begin{array}{c}0.008 \\
(0.016)\end{array}$ & $\begin{array}{c}0.007 \\
(0.017)\end{array}$ & $\begin{array}{c}0.000 \\
(0.018)\end{array}$ \\
\hline Democracy & & $\begin{array}{l}-0.000 \\
(0.008)\end{array}$ & $\begin{array}{c}-0.002 \\
(0.008)\end{array}$ & $\begin{array}{c}-0.003 \\
(0.010)\end{array}$ & $\begin{array}{c}-0.007 \\
(0.011)\end{array}$ & $\begin{array}{l}-0.009 \\
(0.011)\end{array}$ \\
\hline$\times N K$ & & & & $\begin{array}{c}-0.001 \\
(0.018)\end{array}$ & $\begin{array}{c}0.004 \\
(0.019)\end{array}$ & $\begin{array}{c}0.007 \\
(0.020)\end{array}$ \\
\hline$\times N K r$ & & & & $\begin{array}{c}0.019 * * \\
(0.009)\end{array}$ & $\begin{array}{l}0.018 * \\
(0.009)\end{array}$ & $\begin{array}{l}0.019 * \\
(0.010)\end{array}$ \\
\hline$\times N K \times N K r$ & & & & $\begin{array}{c}-0.029 * \\
(0.016)\end{array}$ & $\begin{array}{l}-0.029 \\
(0.018)\end{array}$ & $\begin{array}{c}-0.030 \\
(0.019)\end{array}$ \\
\hline Constant & $\begin{array}{c}0.090 * * * \\
(0.032)\end{array}$ & $\begin{array}{c}0.096 * * * \\
(0.034)\end{array}$ & $\begin{array}{l}0.067 * \\
(0.038) \\
\end{array}$ & $\begin{array}{c}0.099 * * * \\
(0.034)\end{array}$ & $\begin{array}{l}0.071 * \\
(0.039) \\
\end{array}$ & $\begin{array}{c}0.095 * * \\
(0.038)\end{array}$ \\
\hline Demographic controls & Yes & Yes & Yes & Yes & Yes & Yes \\
\hline Other experimental controls & Yes & Yes & Yes & Yes & Yes & Yes \\
\hline Other attitudinal controls & No & No & Yes & No & Yes & Yes \\
\hline Interactions with other attitudinal control & No & No & No & No & No & Yes \\
\hline Observations & 1,790 & 1,758 & 1,634 & 1,758 & 1,634 & 1,634 \\
\hline R-squared & 0.397 & 0.400 & 0.423 & 0.402 & 0.425 & 0.445 \\
\hline
\end{tabular}

Notes. Robust standard errors, clustered by individual subject, are reported in parentheses. *, **, and *** represent $10 \%, 5 \%$, and $1 \%$ significance level. $N K$ is an indicator of NK subject being a decision-maker, while $N K r$ is an indicator of NK subject being a recipient. Demographic controls include gender, four categories of age, and their interactions with the NK dummy. Other experimental controls contain a dummy for Study 1 and the size of session. Other attitudinal controls include national identity, attitudes toward NK refugees, trust/trustworthiness attitudes (GSS), and survey responses on risk taking and experience of being discriminated against. They are also interacted with $N K, N K r$, and $N K \times N K r$ dummies. 